\title{
Bio-Inspired/-Functional Colloidal Core-Shell Polymeric-Based NanoSystems: Technology Promise in Tissue Engineering, Bioimaging and NanoMedicine
}

\section{Ziyad S. Haidar ${ }^{1,2}$}

1 Department of Pharmaceutics and Pharmaceutical Chemistry, University of Utah, 30 South 2000 East, Salt Lake City, UT, 84112-5820, USA; E-Mails: ziyad.haidar@mcgill.ca; ziyad.haidar@unidds.com

2 Department of Bioengineering \& Regenerative Medicine, Utah-Inha DDS \& Advanced Therapeutics Research Center, B-404 Meet-You-All Tower, Songdo TechnoPark 7-50, Songdo-Dong, Yeonsu-Gu, Incheon, 406-840, Republic of South Korea

Received: 16 August 2010; in revised form: 13 September 2010 / Accepted: 16 September 2010 / Published: 20 September 2010

\begin{abstract}
Modern breakthroughs in the fields of proteomics and DNA micro-arrays have widened the horizons of nanotechnology for applications with peptides and nucleic acids. Hence, biomimetic interest in the study and formulation of nanoscaled bio-structures, -materials, -devices and -therapeutic agent delivery vehicles has been recently increasing. Many of the currently-investigated functionalized bio-nanosystems draw their inspiration from naturally-occurring phenomenon, prompting the integration of molecular signals and mimicking natural processes, at the cell, tissue and organ levels. Technologically, the ability to obtain spherical nanostructures exhibiting combinations of several properties that neither individual material possesses on its own renders colloidal core-shell architectured nanosystems particularly attractive. The three main developments presently foreseen in the nanomedicine sub-arena of nanobiotechnology are: sensorization (biosensors/ biodetection), diagnosis (biomarkers/bioimaging) and drug, protein or gene delivery (systemic vs. localized/targeted controlled-release systems). Advances in bio-applications such as cell-labelling/cell membrane modelling, agent delivery and targeting, tissue engineering, organ regeneration, nanoncology and immunoassay strategies, along the major limitations and potential future and advances are highlighted in this review. Herein, is an attempt to address some of the most recent works focusing on bio-inspired and -functional polymeric-based core-shell nanoparticulate systems aimed for agent
\end{abstract}


delivery. It is founded, mostly, on specialized research and review articles that have emerged during the last ten years.

Keywords: tissue engineering; quantum dots; drug delivery; dentistry; core-shell; liposomes; polymer; PLLA; biomedicine; nanoncology; nanofibers; bioimaging; biomimetic; biosensors; bone regeneration; glucose; nanoshell; artificial virus; amphiphilic co-polymers; ligand; micelles

\section{Abbreviations}

$\mathbf{A L}=$ alginate;

BMP-7/OP-1 = bone morphogenetic protein -7/Osteogenic protein-1;

$\mathbf{C d S e}=$ cadmium selenide;

$\mathbf{Z n S}=$ zinc sulfide;

$\mathbf{C H}=$ chitosan;

GOD = glucose oxidase;

HA = hyaluronic acid;

IgG = Immunoglobulin G;

$\mathbf{L}=$ liposome;

L-b-L = layer-by-layer self-assembly technique;

MPS = mononuclear phagocyte system;

MRI = magnetic resonance imaging;

$\mathbf{M W}=$ molecular weight;

$\mathbf{n I R}=$ near infra-red;

NZW = New Zealand White;

$\mathbf{P A C}=$ poly aluminum chloride (cationic);

PCL $=$ poly $(\varepsilon$-caprolactone $) ;$

PEG = polyethylene glycol;

PEO = polyethylene oxide;

PGA = polyglycolic acid;

PLA = polylactic acid;

PLGA = poly(lactic-co-glycolic acid $)$;

PLLA = poly (1-lactide);

PVA = poly (vinyl alcohol);

$\mathbf{P V P}=$ polyvinylpyrrolidone;

QDs = Quantum Dots;

RES = reticulo-endothelial system;

$\mathbf{r h}=$ recombinant human . 


\section{Introduction}

The interplay between nanoscience and nanomedicine continues to be the hallmark of current scientific research worldwide, promising to change every aspect of human life via creating revolutionary materials of biological origin for use in the diagnosis and treatment of devastating human diseases [1,2]. Two of the key factors in determining the successful performance of such multidisciplinary technology are the properties of the surface chemistry and surface morphology; where the bio-inspired material and the biological system meet and interact. Hence, the synthesis of novel biocompatible polymeric-based nanomaterials and nanostructures that are hundreds (or less) of nanometers in diameter provides, through supramolecular surface chemistry, an ability to absorb or bind drugs, receptors, cell adhesive peptides and/or ligands, given their favourable size, rendering them ideal vehicles for drug, protein and/or growth factor delivery [1-3]. Intense effort has been invested into engineering such complex bio-surfaces to achieve optimum cell-material interactions, while keeping intact the materials bulk properties [2,3]. They also seem to offer impressive solutions when applied to clinical challenges like neurological disorders, infectious diseases, diabetes, cancer, cardiovascular and muscoloskeletal problems [2]. By considering the intricate design of natural human body systems and taking advantage of their special physical characteristics, other nanomaterials and nanostructures can stimulate, respond to and interact with target cells and tissues in controlled ways to induce favorable physiological responses with a minimum of undesirable effects $[2,4,5]$. Thus, out of the superfluity of size-dependant properties in the presently-available nanosystems, optical [6] and magnetic [7] effects continue to be the most used for biological applications with significant advancement reported in the fields of drug delivery, gene therapy, novel drug synthesis, bioimaging and detection of cancerous cells [1-3,6,7]. Further, recent progress, especially in core-shell architectured polyelectrolytes- or polysaccharides-incorporated nanostructures, their bio-compatibilization, responsiveness and multi-functionality; make them 'smart' or 'intelligent' and promising in diagnostic medicine, localized, targeted and predictable delivery of active therapeutic agents, soft/hard tissue engineering and organ regeneration [8-10].

In this review, such developmental advances limited to the development of bio-inspired and bio-functional, polymeric-based, core-shell nanosized (mainly, colloidal) systems applied in tackling diverse biomedical problems are presented concisely with a selective focus on the reported simplicity of design, formulation, variation/tailoring, administration, evaluation and translation.

\section{Polymeric-Based Core-Shell Colloids}

Polymers are macromolecules composed of a large number of identical or similar repeating units organized in a chain-like molecular architecture exhibiting a multiplicity of compositions, structures, and properties. Biocompatible and biodegradable polysaccharide-based colloids and bio-colloids are small particles that can range in diameter from 10 to $400 \mathrm{~nm}$ (polymeric micelles are usually between 10 and $50 \mathrm{~nm}$ in diameter) and have been used for various applications since the 1970s. Figure 1 summarizes the advantages of core-shell nanostructures. Structures, constituents, formulation parameters and design can vary and so can the resulting properties and characteristics. Chan and co-workers [10] have formerly addressed advances in the development of polymeric-based nanoparticles. For instance, amphiphilic co-polymers, displayed in Figure 2, are good examples of 
polymers that self-assemble into a core-shell structure. The hydrophilic core serves as a reservoir for genes, enzymes and a diversity of drugs with various characteristics [11]. Thus, such design provides a feasible way to combine multiple functionalities while maintaining the nanoscopic length scale, according to Schärtl [12]. Ranjan et al. [13], recently demonstrated the antibacterial efficacy of amphiphilic core-shell nanostructures encapsulating gentamicin against an in vivo intracellular Salmonella model, for example. Further, novel colloidal systems have been introduced as another means (depending on cross-linker) by which core-shell nanoparticles were synthesized and their final properties such as elasticity and biodegradability modified or improved. A PCL core grafted and surrounded by a hydrophilic dextran shell is a stable colloidal core-shell (offering tri-phasic release) system aimed for biomedical applications. Also, PLA, PLGA, and PCL nanoparticles coated with PEG have been extensively studied for protein adsorption [14]. The PEG chains in the shell add the advantage of a coveted longer blood circulation time than do particles lacking this layer. In addition, those particles are not recognized by cells of the MPS, and therefore can serve as a persistent drug delivery system with potential for in vivo and clinical administration [15]. Basically, this 'camouflage' method creates a hydrophilic protective layer or shell around the nanoparticles that is able to repel the absorption of opsonin proteins via steric repulsion forces, thereby blocking and delaying the first step in the opsonization process [16]. This is the main reason why smaller nanoparticles $(<100 \mathrm{~nm}$ in average diameter, such as polymeric micelles) could avoid recognition by cellular defense systems (such as the RES) after surface modification and therefore, circulate longer in the body [10,16]. Previously, Finne-Wistrand and Albertsson [16] extensively studied such polymeric structures and the use of polymers in the design of resorbable core-shell nanostructures. Figure 3 highlights a few of the relevant synthesis methods for formulating core-shell architectured nanostructures. Further, several pertinent sources of information on the preparatory steps of colloidal core-shell particle systems; mainly via cross-linking mechanisms $[10,15,16]$ are currently available and therefore will not be repeated herein.

Figure 1. Advantages of Core-Shell Architectured NanoSystems in NanoMedicine.

\begin{tabular}{l}
\hline -enhanced formulation monodispersity \\
-decreases or prevents agglomeration \\
-increases encapsulant/load bioavailability \\
-allows improved thermal and chemical stability \\
-allows dose proportionality and reduction of dosing frequency \\
-decreases or diminishes toxicity \\
-allows "simple" conjugation of other molecules, ligands and linkers \\
-enhances formulation solubility \\
-prevents/slows core material oxidation \\
-has higher intra-cellular uptake \\
-facilitates controlled/predictable drug release \\
-allows modulating encapsulant/load release \\
-facilitates/improves molecular bioimaging/biosensing \\
-in vivo circulation might be controlled \\
-allows cell-/tissue-selective targeting \\
•cost-effective?
\end{tabular}


Figure 2. Universal Illustration of Bio-inspired Core-Shell Nanostructures.

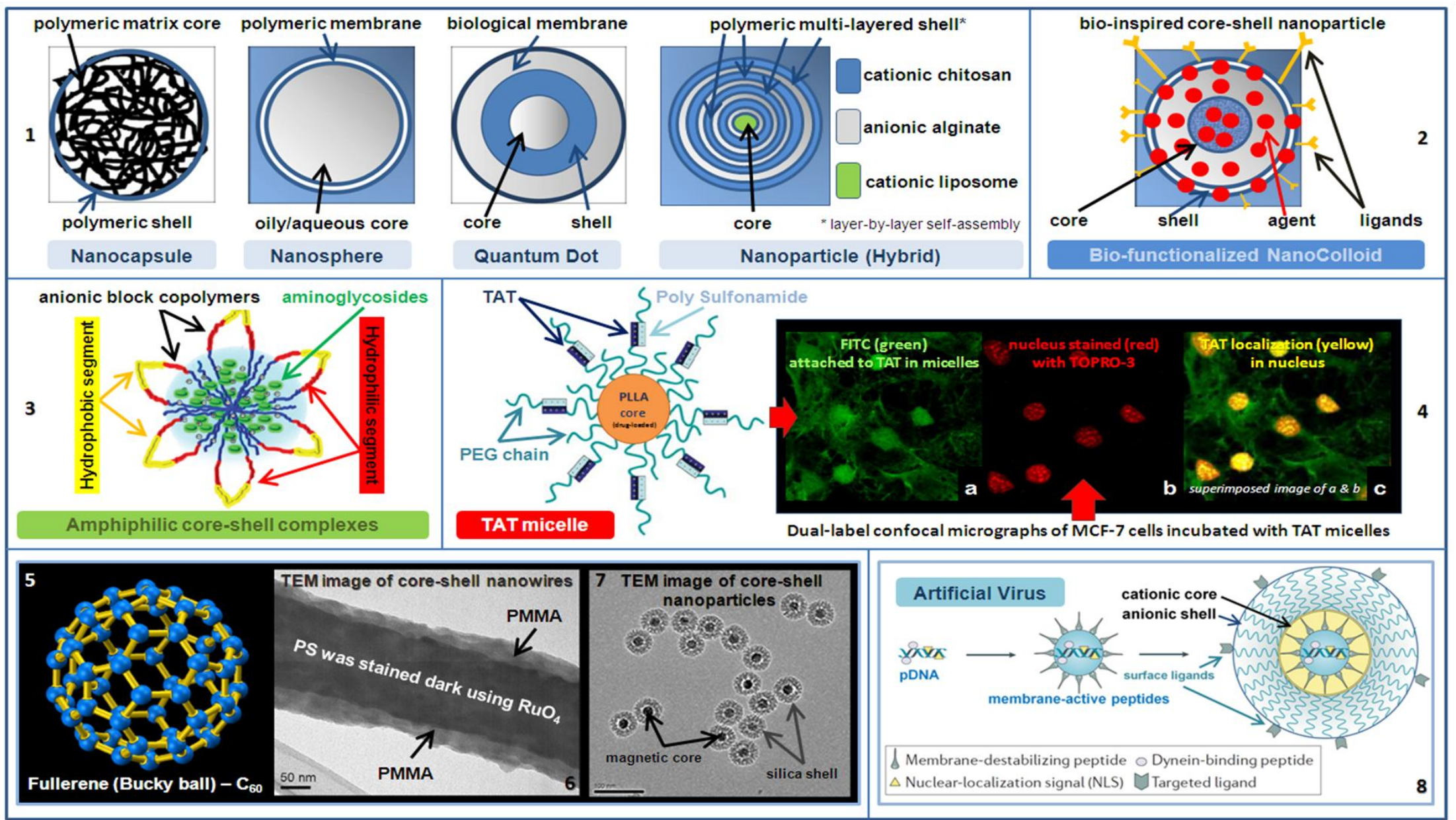

Top row (1 and 2): Spherical nanoparticles with a schematic representation of a layer-by-layer (L-b-L) self-assembled multi-layered nanoparticulate delivery system and a bio-functionalized colloid for targeted drug, protein and gene delivery. Middle row (3 and 4): An amphiphilic polymer core-shell nanocomplex for antibacterial applications and beyond. Balance of the hydrophobic-hydrophilic segment is deemed necessary for the successful and efficient formulation of such nanosystems [13]. The TAT micelle consisting of two components, PLLA-b-PEG micelle conjugated to TAT and a pH sensitive diblock polymer PSD-b-PEG where only PEG is exposed rendering the carrier long circulating and when in tumor environment (pH decrease), 
sulfonamide detached exposing TAT to tumor cells, as shown in the confocal micrographs; modified from [33]. Bottom row (5 to 8): Miscellaneous coreshell architectured nanostructures ranging from the spherical structural arrangement of Fullerene composed of 60 Carbon atoms to polymeric-based nanowire fabricated by melt wetting a multilayered PMMA and PS thin polymer film at $150{ }^{\circ} \mathrm{C} / 48 \mathrm{~h}(\mathrm{Bar}=50 \mathrm{~nm})$ to small and discrete magnetic (core)-silica (shell) nanoparticles combining both, imaging and therapeutic capabilities (Bar $=100 \mathrm{~nm}$ ) to a conceptual illustration of the assembly of a multi-layered artificial virus tailored as an intracellular vehicle; modified from [100].

Figure 3. Selective Preparation Methods for Polymer-incorporated Core-Shell Nanostructures.

\begin{tabular}{|c|c|c|c|}
\hline Synthesis Method & Description and Use & Design and Application Synopsis & \\
\hline $\begin{array}{l}\text { Sol-Gel } \\
\text { (ionic gelation) }^{*}\end{array}$ & $\begin{array}{l}\text { For synthesis of metal or polymer (core) metal oxide (shell) } \\
\text { nanoparticles in inorganic matrix (silica) forming a gel. Also for } \\
\text { some semiconductor nanoparticles (heat treated - gelation) } \\
\text { forming an oxide shell on top of metal or polymeric core. }\end{array}$ & $\begin{array}{l}\mathrm{Fe} / \mathrm{Fe}_{2} \mathrm{O}_{3} \text { and } \mathrm{Cu} / \mathrm{Cu}_{2} \mathrm{O} \text { ) in silica matrix } \\
\text { polypyrole/ } / \mathrm{Fe}_{2} \mathrm{O}_{3} \text { and } \mathrm{CdSe} / \mathrm{CdS} \text { nanoparticles } \\
\text { *also known as complex coacervation [16]. }\end{array}$ & \\
\hline $\begin{array}{l}\text { Reverse Micelle } \\
\text { (emulsification) }\end{array}$ & $\begin{array}{l}\text { For controlling nanoparticle size and morphology via performing } \\
\text { synthesis in emulsions or in solutions that form micelles (by } \\
\text { mixing aqueous reactant with suitable surfactant) followed by } \\
\text { oxidation polymerization and shell coating (Sol-Gel). }\end{array}$ & $\begin{array}{l}\mathrm{Fe} \text { (core)-Au(shell) and } \mathrm{Co} \text { (core)-Pt(shell) } \\
\text { Polymeric nanoparticles synthesized if mon- } \\
\text { omer emulsion is thermodynamically stable }\end{array}$ & In \\
\hline Mechano-Chemical & $\begin{array}{l}\text { Sonochemichal synthesis (chemical reaction for nanoparticle } \\
\text { synthesis and sonication to improve speed of reaction and particle } \\
\text { dispersion) and Electrodeposition (formation of nanoparticle } \\
\text { shell with charged polymers to control nanoparticle size) are only } \\
\text { two of the techniques used mainly for synthesizing core-shell } \\
\text { nanoparticles with magnetic properties. Others can include: } \\
\text { pulverization, colloidal chemical synthesis, mechanical attrition, } \\
\text { layer deposition and reduction techniques. }\end{array}$ & $\begin{array}{l}\text { Metallic shell nanocomposites: } \\
\mathrm{Fe} \mathrm{O}_{3} \text { (core)-Au(shell) and } \\
\mathrm{Fe}(\text { core)-Co(shell) } \\
\text { Non-metallic shell nanoparticles: } \\
\text { Si(core)-PAPBA(shell) and } \\
\text { CuS(core)-PVA(shell) }\end{array}$ & $\begin{array}{c}\text { chemical structure of a } \\
\text { polymeric core-shell } \\
\text { nanoparticle }\end{array}$ \\
\hline Polymerization & $\begin{array}{l}\text { Free radical polymerization (FRP) or atom transfer radical } \\
\text { polymerization (ATRP) have been used with ATRP showing } \\
\text { superiority in terms of molecular weight and particle size control. } \\
\text { ATRP also facilitates the coating of polymers on silica cores. A } \\
\text { third polymerization method is known as chemical oxidation } \\
\text { polymerization (COP) where a monomer is polymerized via } \\
\text { adding the appropriate oxidizing agents. COP is mostly conducted } \\
\text { for metallic nanoparticles and core-shell nanocomposites formed } \\
\text { by a chemical reaction and reduction. }\end{array}$ & $\begin{array}{l}\text { ATRP method: } \\
\text { Au(core)-Si(shell) nanoparticles } \\
\text {-biomimetic approach- } \\
\text { COP method: } \\
\mathrm{Ag} \text { (core)-polyaniline(shell) } \\
\mathrm{Ag} \text { (core)-polypyrole(shell) } \\
\mathrm{PbS} \text { (core)-polypyrole(shell) } \\
\text { Nanocomposites }\end{array}$ & $\begin{array}{l}\text { anofiber } \\
\text { fold }\end{array}$ \\
\hline $\begin{array}{l}\text { Electrospinning } \\
\text { (nanorods/nanowires) }\end{array}$ & $\begin{array}{l}\text { Used to fabricate core-shell nanowires (co-e-spinning) where the } \\
\text { nanofiber core material (by traditional } e \text {-spinning) has been } \\
\text { employed in conjunction with coating processes such as chemical } \\
\text { or physical vapour deposition, spin coating, or spraying to coat the } \\
\text { core with a layered polymer shell. A new template wetting } \\
\text { technique referred to as a template assisted sequential solution } \\
\text { wetting was demonstrated to fabricate core-shell polymer } \\
\text { nanowires with adjustable shell thicknesses. }\end{array}$ & \begin{tabular}{|l|} 
Metallic nanocables (nanoelectric devices): \\
Ag(as conducting core)-Si(as insulating shell) \\
Nanofibers (core-shell polymeric devices): \\
Polyaniline (core)-schizophyllan (coat) \\
in biological sensor applications \\
$\mathrm{PCL}$ (core)-PEG(shell) and Nanospheres- \\
embedded PLLA nanofibrous scaffolds \\
for bioactive protein delivery $[122,127]$.
\end{tabular} & $\begin{array}{c}\text { Nanospheres- } \\
\text { embedded PLLA } \\
\text { nanofiber scaffold }\end{array}$ \\
\hline
\end{tabular}




\section{Bio-Functionalized Core-Shell Designed Nanomaterials and Nanosystems}

Today, complex materials can be prepared to mimic the supramolecular architecture of naturally-occurring structures with the added capability of sophisticated- and/or multi-functions. To simplify, depending on the method of synthesis, material composition and intended purpose/mode of use, nanostructures employed in nanomedicine can be either (a) one-dimensional thin surface films and coatings; (b) two-dimensional mono- or multi-layered carbon nanotubes and colloidal assemblies; or (c) three-dimensional semiconductor spherical nanocrystals (1-10 nm QDs), dendrimers and micelles (1-100 $\mathrm{nm})$, organic spherical cages $\left(\mathrm{C}_{60}\right.$ Fullerenes), nanoshells and/or core-shell nanoparticles [4,17-20] as illustrated in Figure 2. Given this wide array of currently-available and possible material combinations, Sounderya and Zhang [21] have recently classified core-shell nanoparticles broadly based on the material with which the core and shell are made. The colloidal class of materials includes hollow capsules and/or nanoshells in addition to core-shell structured particles. Yet, besides all of the different complexation (biocolloids) and fabrication techniques, what is important to consider is that the necessity to shift from traditional bulk biomaterials, microparticles and nanopolymers to core-shell structured particles within the nanometre size range is in essence, for the overall improvement of optical, magnetic and/or agent delivery properties. In turn, this would result in enhancing particle morphology, monodispersity, preventing agglomeration, reducing toxicity and as a result, allows orchestrating and mimicking those involved bodily complex biological scenarios [18]. Such enhanced surface reactivities can be further modified via coating with various materials for better stability and biocompatibility [20,22]. A simple, well-known and highly-adaptable method is the layer-by-layer (L-b-L) self-assembly technique [20]. By dictating and controlling the type, composition, number and thickness of alternating layers surrounding the core, multi-functional core-shell nanostructures of various MW can be formulated where both, magnetic and luminescent layers can be combined to detect and manipulate the particles in situ [23]. Thus, core-shell designed nanoparticles, specifically, are considered advanced nanostructures offering superior advantages over traditional nanomaterials, giving significance and need for their use [20-23]. Caruso and group have previously highlighted the feasibility and potential of the L-b-L technique in formulating novel particles and modifying basic polymeric bio-inspired colloidal systems [23].

For years, a common approach for nano-engineering core-shell structures has been the use of rigid silica for the core and another 'sticky' compound to adhere gold particles, typically, to the outside surface, creating the shell. Such nanoshells have been used to kill cancer cells in mice, for example [21,24]. Once injected into a tumor, radiation is applied and the nanoshells heat up enough to exterminate the tumor cells [24]. On the other hand, a traditional nano-sized drug carrier would solubilize poorly water-soluble anti-cancer drugs, prolong their circulation time in the blood and have reduced or diminished side effects as well. When further bio-functionalized, conjugated or coated; multi-functional core-shell nanoparticles can perform targeted and controlled delivery [20] as well as serve as superior nanoscopic biomarkers of tumors and cancer cells due to their high enhanced permeability and retention properties [12,20]. The design, therefore, enhances thermal and chemical stability while improving solubility and cytocompatibility and consequently allowing the conjugation of other bioactive molecules [25]. This continues to be an intense research area for cancer therapy. Alternatively, semiconductor cores comprised of QDs are being surrounded with shells made of 
semiconductor material, metal oxide or polymeric material like silica for fluorescent bio-imaging applications in biology and medicine [26]. Now, QDs (CdSe: cadmium selenide cores; most frequently used) are most commonly being conjugated to proteins, nucleic acids or other biologically-relevant molecules to serve as molecular targeting devices used in diagnosis and molecular detection, profiling and signal transduction studies [27]. Such novel nanoscopic multifunctional bio-systems have been suggested to be useful tools for mapping the lymphatic system and sentinel lymph nodes, which are important structures in cancer therapy [28,29]. Other studies have revealed that PEGylated-QDs (polyethylene glycol, a FDA-approved biocompatible and biodegradable co-polymer) escape the RES emphasizing the protectiveness of the nanoshell; providing a unique opportunity for extensive use in animals and humans [10].

Consequently, the most promising core-shell nanostructures can be considered to be those 'polymeric-based' comprising a polymeric core and/or a polymeric shell and can be dispersed in a matrix of any material class whose property is to be modified or enhanced. For example, polymeric-based micellar systems which contain a hydrophobic core surrounded by hydrophilic polymers and are typically assembled from amphiphilic di-block or tri-block co-polymers have been extensively explored as carriers for hydrophobic drugs [30]. They offer relatively simple preparation, efficient drug loading and controlled release kinetics. Several drug formulations of commonly used chemotherapeutic drugs such as Doxorubicin [31] and Paclitaxel [32] are currently in various phases of testing in clinical trials. Furthermore, multi-functional, 30-50 nm, core-shell nanospheres comprised of amphiphilic co-polymer micelles (hydrophobic block copolymers) whose core house bio-functionalized $\mathrm{Au}$ or CdSe nanoparticles have been prepared and protected with a PEG coating (hydrophilic block), providing nanoscopic sensing and slow-targeted drug release [12]. On the other hand, Bae et al. [33] have been for years investigating 20-45 nm polymeric-based micelles that comprise a hydrophobic PLLA core and a hydrophilic PEG shell conjugated to TAT; an ultra $\mathrm{pH}$-sensitive and cell penetrating polymer. As shown in Figure 2, the TAT-micelle seems attractive for targeting acidic solid tumors via its demonstrated concentration para-nuclei [33].

\section{Bio-Inspired Polymeric-Based Core-Shell Nanoparticulate Systems}

Natural polysaccharides- and liposome-based core-shell nanoparticles offer interesting alternatives to many of the other complex and synthetic nanostructures and have been long studied as the drug delivery vehicles of choice with the core-shell properties tailored towards specific biomedical applications. Such particles can take various forms including capsules and matrices, to name a few [10]. Polymeric capsules comprise a polymeric outer membrane surrounding a hollow core, similar in basic structure to liposomal vesicles. On the other hand, matrix-based systems are formed via interactions between several polymer chains, resulting in the formation of a 'net-like' complex with inter-chain pores (sponge-like structure also referred to as nanosponges) suitable for the gradual and sustained release of the entrapped load within [34]. Therefore, nanoparticle synthesis and preparation is dependent on many factors, most importantly, the polymer(s) used, of which there is an abundance to choose from, according to the intended application [35] (refer to Figure 3). Intelligent, smart or stimuli-responsive polymer-based systems in the form of cross-linked or physical gels covalently linked onto surfaces that reversibly alter their physico-chemical characteristics in response 
to their environment have been the center of recent intensive exploration [36]. Some examples include light-responsive (photo-thermal) hydrogels incorporating gold nanoshells, polymer-supported liposomes for cell membrane modeling and other injectable, bio-functional/bio-inspired self-assembling systems in targeted drug/gene delivery $[8,9,20,23,37]$ which can be accomplished via grafting or surface complexation with specific ligands (such as antibodies, aptamers, peptides, other polysaccharides, etc.). Surface functionalization will be further discussed later. For many years, liposome-based core-shell designed preparations have found applications in cell membrane modelling, drug and growth factor delivery as well as transfection; overcoming past shortcomings associated with cytocompatibility, malleability, stability and the phospholipid vesicle size, monodispersity and membrane permeability, via the L-b-L incorporated-support of polyelectrolytes [20,23]. Other investigators have even explored coating polymeric core-shell particles with different asymmetric bi-layer as well as inorganic-based phospholipid membranes such as poly(diallyldimethylammonium chloride) and poly (sodium 4-styrenesulfonate) [38]. Such systems have found suitability for studying membrane recognition, signal transduction processes as well as controlled drug release [38,39].

Now, while traditional nanoparticles with hydrophobic surfaces are rapidly opsonized and cleared by the bodily reticulo-endothelial and mononuclear phagocytic systems, targeted therapeutic delivery requires the persistence of nanoparticulate systems throughout the systemic circulation of the body [40]. For that reason among others, modification and coating of surfaces with different cationic materials and hydrophilic polymers to promote nanoparticulate-cell interaction and cellular internalization have been deemed desirable [32]. Coatings (nanoshells) create a cloud of chains at the nanoparticle surface which repels plasma proteins [41]. Alginate, chitosan, gelatin, hyaluronic acid, PLGA, PLA, PCL and PAC are some examples of biodegradable polymers used and intensively investigated in the formulation of polymeric-based core-shell nanoparticles, mainly as drug, protein and gene delivery vehicles [10,15,42-44]. Their bioavailability, enhanced encapsulation, controlled release and cyto- and bio-compatible properties improve the therapeutic value of nano-encapsulated agents. The impact of various significant nanomedicine biomolecules and nanotherapy drugs upon encapsulation in such biodegradable nanosystems was just highlighted by Kumari and group [15]. Challenges in biodegradable nanoparticulate systems, mainly aimed for the delivery of growth factors such as bone morphogenetic proteins were reviewed as well $[8,9]$. The performance of nanoparticles in vivo will be influenced by size and morphological characteristics, surface charge and chemistries, and molecular weight of polymers involved $[45,46]$. Surface-modified liposomes with alternate coats of alginate and chitosan, by virtue of the extended configuration on the particle surface acting as a barrier or a spacer, reduced the extent of agglomeration and possibly clearance by circulating macrophages of the liver upon administration in vivo [20,46]. Further, the core-shell structure allowed for modulating the release mechanism from the nanoparticles via controlling the number of layers forming the shell [20,45,47]. Additional control can be accomplished by modifying the MW of the polymers used where it has been shown that, the higher the MW, the slower the in vitro release of drugs will be [47].

\section{Bio-Inspired Surface Chemistry and Bio-Functional Tailoring}

In core-shell designed nanostructures and nanoparticles, agents, biomolecules and/or drugs are normally either entrapped within the shell, encapsulated/protected inside the core and/or conjugated to 
the particle surface [16]. The latter is probably dictated by the mechanism of targeting sought; thereby, passive versus active. The unique 'tiny' sizes of nanoparticles are acquiescent to surface functionalization or modification to achieve the desired characteristics for a specific application. And so, various methods have been employed to enhance load or cargo retention time, reduce non-specific distribution and target tissues or specific cell surface antigens with targeting ligands, aptamers, peptides and antibodies. Yet, in targeted drug delivery, nanoparticle surface modification remains a very important and ongoing investigational and developmental approach to release drugs in the blood stream with invisibility or "stealth" against the natural defense system of the body (opsonisation), as mentioned earlier [40]. Logically, longer circulation time will increase the probability for the nanoparticles and their respective loads to reach their intended targets. However, it is noteworthy that surface modification, synthesis and choice of polymeric materials for formulating nanometric coreshell carriers are entirely dependent on nature of drugs, delivery periods, stability, permeability and drug release profiles [48]. Therefore, if sustained systemic circulation is required then the surface of hydrophobic nanoparticles must be modified in order not to be rapidly collected in the liver or spleen [46]. Surface modification can be via coating the core with a static hydrophilic protective layer, such as PEG, PVP or chitosan derivatives that prevent macromolecules from interacting with the nanoparticle, even at low surface coverage to release their load at a specific site $[16,40]$. The accumulation of drug-loaded nanoparticles at the target site is more important than their circulation and retention in the circulatory system of the body. Passive and active targeting techniques have been described elsewhere [16,40,49]. Briefly, in passive targeting, nanoparticles accumulate at tumor sites due to their (of the tumor that is) leaky vasculature; while in active targeting, the nanoparticles will have to carry targeting molecules on their surfaces to interact with the surrounding tissue. An example of active surface modification is the use of an $\mathrm{IgG}$ shell to enhance the immunoresponse of the core [50]. On the other hand, hydrophilic polymers can be tailored to nanoparticle surfaces in two main ways; adsorption of surfactants or through the use of branched co-polymers. In one example, dextran was used to coat the surface of PCL nanoparticles to inhibit protein adsorption [16]. Furthermore, poly(N-isopropylacrylamide) co-polymer introduced on to the surface of PCL nanoparticles formed a hydrogel layer and provided an additional diffusion barrier. Ligand-shellgrafting to specific target receptors have been tested mostly, thus far, with members from the lectin family; where the involvement in many cell recognition and adhesion processes being the main rationale [16,48-51]. Moreover, heparin (2 to $50 \mathrm{kDa} \mathrm{MW}$ ), a well-known anti-coagulant and platelet agent, is probably the most extensively investigated and covalently immobilized polysaccharide for modifying biomaterials (mainly blood-contacting) such as polylactides, polyvinyl alcohols and polyurethanes, to name a few [52]. Also, growth and differentiation polypeptides such as epidermal growth factor, basic fibroblast growth factor and members of the transforming growth factor beta family have been covalently immobilized to surfaces of polymeric materials, particles and structures for tissue engineering and regenerative medicine applications [52,53]. Growth factormodified biomaterials have included PEG-based hydrogel scaffolds, poly(methyl methacrylate), polystyrene and the use of star PEG spacer molecules to immobilize the peptide to the biomaterial or particle [52-55]. This approach seems to sustain prolonged availability and targets activity to sites of interest in wound healing, bone induction, regeneration and repair [55]. 


\section{Biomedical Applications of Core-Shell Polymeric-Based Nanostructures}

\subsection{Bio-Sensing in Diabetes Mellitus: Glucose Level Monitoring}

Diabetes mellitus is a chronic disease characterized by hyperglycemia caused by the defective action and/or under-secretion of insulin, exacerbating complications such as nephropathy, neuropathy, retinopathy and cataract [56,57]. Nano-biosensors are being explored for the life-time management of diabetic patients where glucose levels can be measured accurately in blood, in a non-invasive fashion [57,58]. For example, glucose oxidase (GOD) coupled to core-shell nanotubes have been recently shown to serve as catalytic biomolecular sensors [59,60]. A single-molecule detection for the study of molecular diversity in diabetes pathology has been explored [57]. Also, the feasibility of a novel ultrasensitive protein nanoprobe system based on self-assembled supra-molecular protein nanoparticles (10-15 nm) that would bind GAD65 (antibody - an early marker of Type I diabetes) during the early phase of pancreatic $\beta$-cell destruction was investigated. This system has the potential of identifying high-risk individuals several years before the clinical onset of Type I diabetes [61]. Duong \& Rhee [62] also recently synthesized CdSe/ZnS core-shell QDs and conjugated them with specific enzymes; GOD and HRP for use as probes to biosense or detect blood glucose levels. On the other hand, a France-based research group headed by Ravaine [63] recently synthesized novel multi-responsive core-shell structured microgels to encapsulate insulin and have showed a response to glucose (via core swelling) at physiological $\mathrm{pH}$ while controlling insulin release (via shell compression) proportional to glucose concentration. The microgels comprised a thermo-responsive core and a glucose-responsive shell, made of poly(N-isopropylacrylamide) and poly $(\mathrm{N}$ isopropylacrylamide)-co-acrylamidophenylboronic acid, respectively [63]. Then again, biocompatible and biodegradable $\mathrm{pH}$-sensitive alginate nanospheres releasing insulin over extended periods in less acidic intestinal environments (but not in acidic gastro-environments) are undergoing development [64]. Moreover, self-assembled glucose oxidase and an osmium molecular wire on core-shell gold nanoparticles were shown to be responsive to glucose levels. The multi-layered shell have been demonstrated to function as a multi-layered biosensor with superior sensitivity and enhanced biosensor signal [65].

\subsection{Bio-Imaging: Biological and Cell Membrane/Intra-Cellular Labelling}

Bio-imaging applications of core-shell designed nanostructures may include cell (and -constituents) recognition and labelling/sorting, oligonucleotide and single bacterial cell detection and single cell $\mathrm{pH}$ nano-sensing. Carbon nanotubes, fullerene derivatives, and nanocrystal QDs have received widespread application as novel tools in various fields ranging from materials engineering, electronics, plastics, automobile and aerospace industries, to molecular biology and medicine [17]. In nanomedicine, a current prominent challenge is evaluating the real time distribution and fate of nanoparticlulate systems and their constituents in tissues and organs of the body and more importantly within individual cells $[1,5,8,9,29]$. At present, luminescent core-shell nanostructures such as QDs, magnetic nanoparticles and other nano-scaled biomarkers have been tested in most biotechnological applications that involve fluorescence and luminescence, including DNA array technology, immunofluorescence assays, MRI and cell and animal biology (vascular and lymphatic systems tumor cell labelling), given 
their superior photo-emission and -stability capabilities [29]. As they tend to target and penetrate cells easily and enjoy a better spin-lattice relaxation time, biocompatible core-shell magnetic nanoparticles with $\mathrm{Fe}_{2} \mathrm{O}_{3}$ or cobalt core have been used to enhance MRI contrast and subsequent imaging quality [66]. Recently, thermo-responsive polymer-coated magnetic cores were loaded with anticancer drugs (doxorubicin) for magnetic drug targeting followed by simultaneous hyperthermia and drug release (multi-modal treatment of cancer) with good results [67]. Also, nanocomposite biomarkers have the ability to operate at wider $\mathrm{pH}$ and temperature ranges [68]. The high-detection benefits of using QD-based labels in (sandwich immunocomplexes) immunoassays [69] were realized by exploiting their spectral multiplexing capability to excite and detect several labelled species simultaneously using a single light source [70]. Many studies have shown the promising potential of using QDs as new probes, in vitro and in multi-cellular animal models; allowing real-time, continuous and prolonged (over periods of hours to days) monitoring and tracking of single and/or multiple cellular components and biological processes. This was not possible to achieve previously with luminescent particles that work in the visible or near-IR (nIR) range [67]. The modern trend is therefore, to benefit from novel core-shell nanostructures that emit in the UV-visible range with low signal to noise ratios suitable for wider and more specific cellular detection [49,50]. The Canada-based Maysinger and co-workers [71] were able to examine in multi-color, the intra-organelle (lysosomes and lipid droplets) distribution of highly-luminescent indium gallium phosphide-zinc sulphide or InGaP/ZnS-coated nanoparticles in cortical brain-originated live primary neural glial cells [71]. Findings reported the suitability of the formulation for both, single-cell and whole-animal real-time imaging [71]. Moreover, modifying surfaces of currently-available QDs are being performed in parallel. The L-b-L self assembly of natural polymers surrounding QD-containing liposomes are being studied (unpublished data). Brighter, multi-functional core-shell nanoparticles (magnetic and luminescent capabilities for cellular labelling and separation), which provide anti-stokes emission such as semiconductor nanoparticles, lanthanide-based nanoparticles and gold-coated silica nanoparticles to name a few, have been receiving increasing interest $[21,27]$ with proper caution to the choice of core and shell material deemed necessary to help obtain clearer three-dimensional images. Further, conjugated-QDs to secondary antibodies, for instance, have been shown to improve Western blot assays when compared to expensive and traditional radioactive labels when used in the ultra-sensitive detection of tracer proteins [72,73]. This, along with the potential to greatly reduce background autofluorescence of biological samples, seems promising towards advancement to the next generation of inexpensive and better flow cytometer systems, probes, assays and diagnostics. Separation and purification of biological molecules and cells are also areas in which such particles with well-defined and controlled properties are used $[49,73,74]$. For example, currently in neuromedicne, developing a method or tool to trace the intra-cellular pathways taken up by sphingolipids and rafts is of great clinical and scientific interest, given the link between lipid raft-borne sphingolipids alterations and neurodegeneration. Consequently, developing a sphingolipid/raft-targeting peptide and formulating core-shell nanomaterials to detect and/or bind antibodies covalently is a sought after diagnostic/therapeutic ultimatum [75]. 


\section{Associated Safety Issues}

One of the main promises of nanobiotechnology is the inception of methodologies, strategies, techniques and tools (complementing cancer diagnostics, for example) that allow using safe, non-invasive, high-resolution/sensitivity and cost-effective modes. Now, although most of the physical and chemical properties of QDs have been very attractive, issues regarding the toxicity (and insolubility) of the core constituent chemicals (such as cadmium and selenium) have been identified with possible harmful effects on human health raising serious concerns. Studies of QDs cytotoxicity are available [68,76] and therefore will not be repeated in detail here. To summarize, size, charge, concentration, outer coating bioactivity (capping material and functional groups), and oxidative, photolytic, and mechanical stability have each been implicated as determining factors in QDs toxicity [68,76]. Furthermore, it is well-established that QDs contain cytotoxic elements; such as cadmium ions [68]. Hence, in 2006, Evident Technologies announced the commercial-availability of QDs that contain no heavy metals. Yet, QDs cytotoxicity has been mainly reported to be exacerbated by their large exposed surfaces (photolysis or oxidation). And so, the most important aspect of QD toxicity is their stability, in vivo as well as during synthesis and storage $[68,76]$. To avoid such shortcomings; employing QDs in biological fluids, modulating the chemical nature of QD surfaces, altering their solubility and adding further chemical functionalities have been explored [68,76,77]. To this end, different coating technologies of biological surfaces, silica and polymeric nanoshells and traditional layers consisting of $\mathrm{ZnS}$ compounds have been incorporated to QDs [77]. This is being done not only to obtain water-soluble QDs but also functionalized nanocrystals fulfilling several tasks such as receptor targeting or sensing of low molecular weight substances. Polymers have been shown to enhance QD stability and function [77]. Developments in synthesis/bioconjugation and effects of the QD-polymer coating (ligand-exchange vs. -capping) have been just described in detail elsewhere [80-83]. Lately, Susumu et al. [78,79] applied a polyethylene surface coat to QDs (a biotincoated surface reacting with streptavidin-coated QDs) and demonstrated enhanced fluorescence intensity [78], stability and biological functionality [79]. In other works, the effect of PEG-coated cationic CdSe/ZnS QDs was demonstrated in live cells. The PEG shell enhanced the long-term stability of the nanoparticles over a broad $\mathrm{pH}$-range and the amine-functionalized core revealed as a result; efficient intracellular labelling [80]. Further, in nude mice, hyaluronic acid (HA)-conjugated QDs [81] were subcutaneously administered and tracked in real-time. nIR wavelength of $800 \mathrm{~nm}$ could be detected up to 2 months stressing functionalization to enhance biocompatibility [82].

\section{Nanoncology}

Besides the thus far demonstrated promise of core-shell nanostructures in early tumor detection and therapy, a major disadvantage of known anti-cancer drugs is their lack of selectivity for tumor tissue, which can lead to severe side effects and low cure rates [84]. Polymer colloids have been used in cancer therapy, as described earlier. While several different attempts have been made to minimize the toxic effects of most anti-cancer drugs, the unique properties of nanoparticles are being exploited for the treatment of tumors. They seem to help in reducing the devastating and adverse effects of chemotherapy [85-87]. Multifunctional nanoparticles that can (a) provide prolonged circulation times, (b) grant specific targeting and accumulation in tissues, (c) illuminate the targeted site and 
(d) intelligently (in terms of selectivity and mode) dose the pathological zones will enable major advancements in diagnosis and therapy. Photodynamic therapy is an effective and selective way to destroy diseased tissue without damaging adjacent healthy regions where the nanoparticles have been actively taken up by the tumor cells and irradiation with visible light has resulted in the irreversible destruction of such impregnated cells [84]. To address some of these issues, several nanosized liposomal and polymer conjugate- based drugs are currently in clinical trials [88]. Notably, polymericbased core-shell nanoparticles can serve as multifunctional therapeutic agents, instead of being utilized as simple passive carriers of drug cargo. Such 'smart' or 'intelligent' systems can potentially carry drugs to the target tissue, image those tissues and release the drug in response to a signal or upon reaching the appropriate cellular compartment [85-87]. Further, targeted nanotherapy may be achieved by coupling a specific antibody or a small molecular weight ligand (such as folic acid) to the surface of the nanoparticle that recognizes a protein selectively expressed on tumor cells [86,87]. To this end, magnetic iron oxide particles or polymeric-based nanotubes may be used as core nanostructures where imaging can be accomplished through MRI with iron oxide nanoparticles or fluorescence methods with QDs while targeting achieved by the functionalized shell. For example, a tumor-targeting antibody, Herceptin (prepared against HER2 receptor amplified in breast tumors), was coupled to gold nanoshells. This enabled targeting HER2-overexpressing tumor cells and when irradiated, tumor cells were specifically killed $[89,90]$. Nanoshells of ultra-thin gold layers surrounding a core of silica were investigated. By adjusting the core and shell thickness, nanoshells can be designed to absorb and scatter light at a desired wavelength [91]. Nanoshells for cancer therapeutic purposes have been designed to have a peak optical absorption in the nIR, as this is the wavelength that optimally penetrates tissue. The metal shell converts the absorbed light into heat with great efficacy and stability. Due to their small size, nanoshells are preferentially concentrated in cancer cells as a result of the known enhanced permeation and retention effect. Supplementary specificity can be engineered by attaching antigens on the nanoshells which are specifically recognized by the cancer cells [90]. Further, the ability of PEG-based $\mathrm{C}_{60}$ fullerenes to generate highly reactive singlet oxygen has also been tested as a potential photodynamic therapy of tumor cells [21]. On the other hand, colloidal ferrofluids consisting of nanosized magnetic particles are being increasingly employed in biomedical applications; especially in nanoncology, as highlighted above. Utilizing the reverse micelle method, Kayal and Ramanujan [92] have recently synthesized doxorubicin-loaded gold shell-iron core nanoparticulate carriers for use in magnetic drug targeting with an up to 25\% demonstrated release of adsorbed anti-cancer doxorubicin within 80 hours, in vitro, while exposed to an external magnetic field [92]. Thus, the concept of multifunctional and multimodal nanoparticles for non-invasive tumor detection and overall cancer therapy has been validated in several experimental systems with hopeful prospective for great future advancements. This, in part, still awaits the inception of a reproducible and well-characterized large animal model that would serve as a proper translational medium from bench to the bed side; where if one considers the current limits and discrepancies associated with the commonly-used lab animal, it would soon be realized that much more should, can and will be done. 


\section{Drug- and Gene-Delivery in Tissue Engineering and Regenerative Medicine}

Whether conventional small-molecule agents or emerging protein and/or peptide-based macromolecular biopharmaceutics, therapeutic effect is of vital significance and controlled or at least predictable delivery is also substantially essential [8,9]. Hence, one of the core interests of nanobiotechnology this decade has been drug/gene delivery [1]. It has been for long reported that a successful delivery system should offer as a minimum, at least one out of three benefits: therapeutic outcome enhancement, patient compliance improvement or overall cost reduction. The characteristics of an 'ideal' delivery system were extensively reviewed previously [8,9]. In the context of this review, bi-functional core-shell nanostructures composed of a luminescent core and a shell conjugated with a biomolecule/drug have been used for targeting/drug delivery and imaging. On the other hand, drug-eluting contact lenses have benefited from such advances and polymeric-based hydrogels have been introduced as ophthalmic drug delivery systems to treat glaucoma [93,94]. To date, many nanoparticles have been investigated for drug delivery however only a few obtained FDA approval [95]. This is predominantly due to their potential toxicity, poor biocompatibility, instability in vivo, low drug loading capacity, or batch-to-batch inconsistencies in their bio-physico-chemical properties [81,95] Polymeric-based core-shell nanoparticles find increasing applications in the biomedical and pharmaceutical areas mainly to overcome such limitations in addition to the problem of poorly-soluble drugs or to obtain long-acting injectable formulations and specific drug-targeting options [8,9]. They can provide controlled release properties due to the biodegradability, $\mathrm{pH}$, ion and/or temperature sensibility of polymers (stimuli-responsive polymers) [96-98]. Polysaccharidesbased core-shell nanoparticles can also improve the utility of encapsulated drugs and reduce toxic side effects [20,99]. Presently, such nanoparticles have been widely used to deliver expensive drugs, polypeptides, proteins, vaccines, nucleic acids and genes $[9,20,99]$. It is noteworthy herein that artificial viruses [100], illustrated earlier in Figure 2, are promising complex gene delivery systems which remain today at their infancy with the most prominent limitation to date being stability, in vivo and intra-cellularly [100]. Briefly, they consist of a cationic core (plasmid DNA/functional peptides) and an anionic shell (targeting ligands can be attached for internalization via endocytosis). Nonetheless, the modern trend in advanced nanoparticulate drug delivery system research seems to maintain focus on the (a) combination of polymer materials to obtain suitable and proper drug release profiles and kinetics; (b) optimization of drug encapsulation efficiencies and loading capacities; (c) shell modification to enhance specific targeting capabilities and (d) optimization of preparatory techniques for clinical use and industrial production. This is especially true in light of the many emerging protein-, peptide- and nucleic acid-based therapeutics. Those are potent, however very expensive and labile. Therefore, their targeted delivery to organs, tissues or cells in an efficient, controlled, predictable, safe, and patient-/physician-friendly manner remains a major research challenge. To this end, numerous polymeric materials have been investigated including PGA, PLA, chitosan, alginates, poly(acrylic acid) family, proteins or polypeptides (such as gelatine and fibrin). Among them, polysaccharides continue to be the most popular polymeric materials for the preparation of core-shell nanoparticles for drug delivery applications [8,9,20,96-99]. Yet, material choice will 
almost always decide the desired multifunctional nature of the resulting particles. Recently, Liu et al. [101] reviewed an exhaustive range of polymers as polysaccharides-based nanoparticulate drug delivery systems and Mano [102] presented the general aspects of the different types of stimuli that can be used to modulate biological response using stimuli-responsive polymeric (natural and synthetic) systems with a look into their biomedical applications. Furthermore, in an informative effort, Hennink and group [98] examined several examples of the most commonly-investigated in situgelling and photo-polymerizable hydrogel-based systems and their potential in biomedicine.

\subsection{Bio-Inspired Polymer-Based Drug Delivery Systems: The L-b-L Self-Assembly}

A while ago, the idea of polyelectrolyte coatings obtained by the alternate deposition of polyanions and polycations emerged as a novel way to functionalize surfaces [103, 104]. This was quickly applied to the drug delivery field where the L-b-L technique extended from the build-up of multi-layered polyelectrolytic films on macroscopic flat substrates [105] to the construction of bio-inspired core-shell particles on various spherical templates and colloidal particles [106]. However, particle flocculation or aggregation was difficult to overcome and thus far, the adsorption of only a single layer of biopolymer, such as PVA [107] or chitosan [108] on a charged liposomal surface has been reported. In addition to being non-toxic, biocompatible, biodegradable and hydrophilic, Tabrizian and co-workers have previously shown that biomolecules could be assembled and entrapped within polyelectrolyte layers, hence maintaining their bioactivity [103,109]. The same McGill University BIOMAT'X group, highlighted earlier, has also been active in designing and formulating alginate-chitosan nanosized polyionic complexes specific for gene therapy [110]. Besides the known advantages including the size property, longer shelf life and ability to entrap more drugs [111], nanosized systems reside longer in circulation, and therefore greatly extend the macromolecular biological activity when compared to microparticles [112]. Their recent findings have pioneered the use of the L-b-L self assembly technique as a simple and effective way to enhance the bioactivity of encapsulated drugs, growth factors as well as the QDs/MRI contrast [71]. The incorporation of local-acting growth factors such as bone morphogenetic proteins (BMPs) within polymer-based core-shell nanoparticulate systems, for example, results in advanced positive effects. Such potent cytokines have been shown to induce tissue regeneration [45-47,113]. Also, when used in injectable delivery systems, a localized, predictable and metered release (deemed necessary for maintaining the bioactivity of such expensive and unpredictable morphogens, given their necessary common use in large supra-physiological dosages associated with unknown long term effects) of the growth factor can be achieved [45-47]. The advantages of nano-scaled liposomes and natural polysaccharides-based polymers namely sodium alginate and chitosan were combined with those of core-shell nanoparticles and hydrogels to formulate novel biocompatible and biodegradable drug and gene delivery system with applications in the field of bone tissue engineering, cardiovascular disease and beyond [20,45-47,114]. Ionic gelation is a method particularly suited to water-soluble polymers (other techniques have been described earlier in Figure 3) and can result in an injectable gel $[45,46]$ or be applied with the L-b-L self assembly of polyelectrolytes to develop multifunctional two- and three-dimensional drug delivery 
systems such as: Paclitaxel nanocoatings on stents (drug-eluting stents) to protect against abrasion as well as prevent thrombogenesis, restenosis and control the arterial healing processes [114] and alginate-chitosan nanoparticles for their potential application as DNA carriers [110,115]. The impact of the core-shell design represented in Figure 4 in protecting encapsulated loads from biodegradation and the benefit of polymers such as chitosan in localizing, modulating and sustaining agent release and any likely side effects (tissue distress) have been demonstrated in diverse in vitro and in vivo studies utilizing small and large animal models over prolonged periods of 70 days $[45,46]$ with an attractive potential for clinical application in skeletal indications such as distraction osteo-, dento-, histio-genesis as well as fracture healing, non-union and repair [9].

Figure 4. Synopsis of some previous works studying the development of novel L-b-L self-assembled Core-Shell Hybrid Nanoparticles.

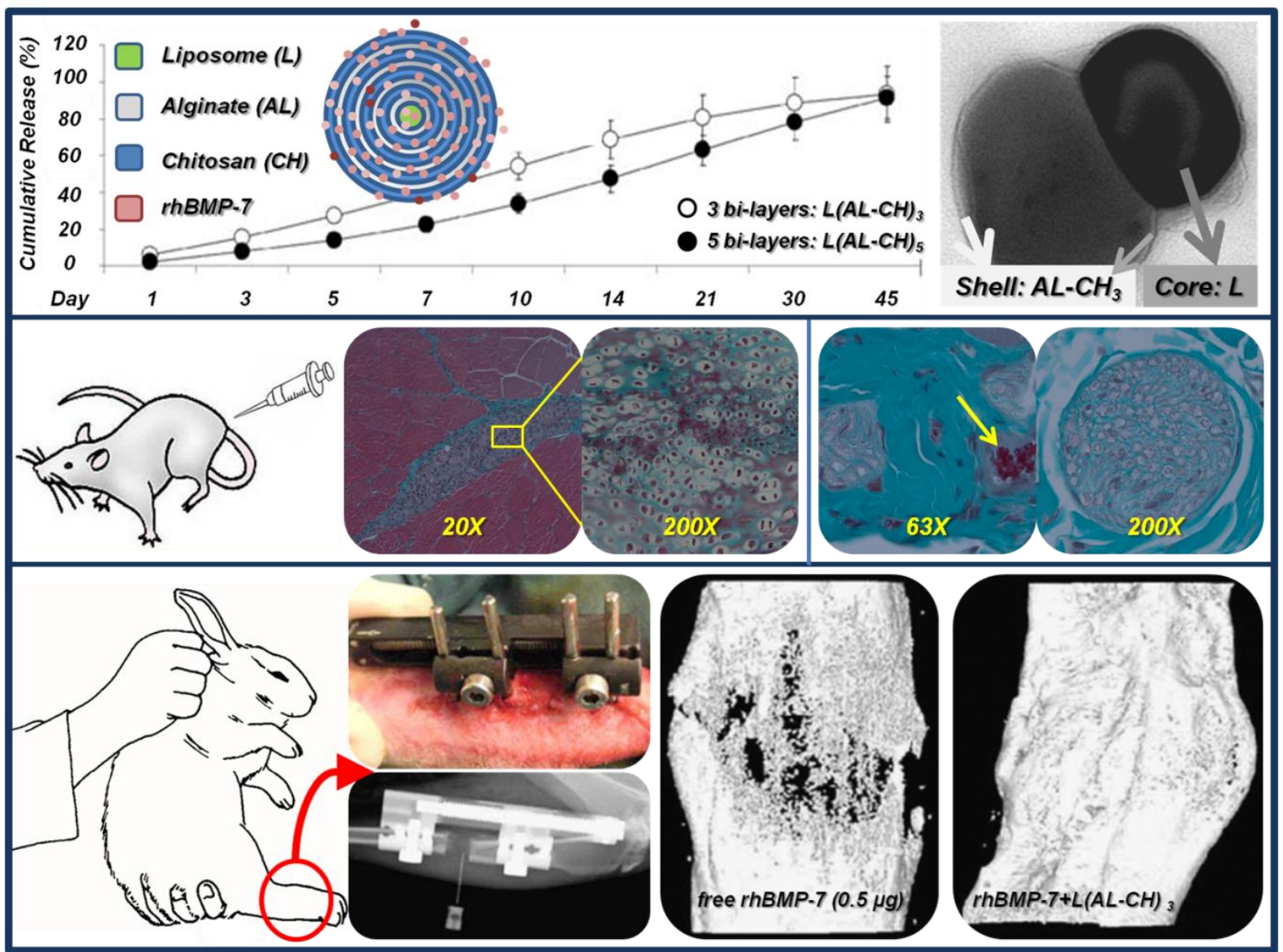

Top row (in vitro): Sustained core and shell linear release of $0.5 \mu \mathrm{g} / \mathrm{mL}$ rhBMP-7 [20,47] that can be modulated via tailoring the number of polymeric layers in the shell where a slower release profile results from the thicker and denser shell). Middle row (biocompatibility): In a normal WISTAR rat toxicity model, timely/complete blood and major organ function analysis was done over a period of 70 days with favorable findings [46]. Histology of injection site in muscle demonstrates the localization effect of the nanoparticles (composition and release effects) where no blood vessel, nerve ending or tissue distress was noted in any of the harvested samples. Bottom row (efficacy in protein delivery): In a NZW rabbit model of long bone distraction osteogenesis [45]; rhBMP-7 loaded nanoparticles accelerated new bone regeneration and consolidation following a single injection. 


\subsection{Synthetic and Composite Drug Delivery Systems: Bio-Functional Nano-Shells}

Many potent drugs are poorly soluble in water leading to either low bioavailability or resulting in a need for a dosage form. In turn, this causes significant adverse side effects including acute hypersensitivity reactions, commonly reported with the use of Paclitaxel when delivered with Cremophor EL [116]. As described thus far, it has been also shown that nanoparticulate systems aid in reducing the adverse effects of chemotherapy in cancer studies [85-87]. These systems are made by forming drug-polymer complexes in which the drug is uniformly dispersed or by creating nano-scaled vesicular cores such as liposomes and micelles to entrap drug molecules [117,118]. The ability of liposomal-based formulations to encapsulate hydrophilic therapeutic agents such as the chemotherapeutic Docetaxel at high loading efficiencies and to shield the load from external conditions can be further enhanced by the application of a shell composed of inert and biocompatible polymers such as alginate, chitosan and PEG [117]. This significantly reduces their systemic clearance rates and prolongs circulation half-life in vivo, as described earlier. PEG-end groups in the shell may also be functionalized with specific ligands for targeting to specific sites of the cells, tissues and organs of interest [20]. Recently, Chan et al. [118] have been developing self-assembled lipid core-polymer shell hybrid nanoparticles for potential use in controlled Docetaxel delivery. The delivery system was synthesized by a modified nanoprecipitation method combined with the self-assembly of three biomaterials: biodegradable PLGA as a hydrophobic core, soybean phosphatidylcholine (lecithin) as a monolayer surrounding the core and 1,2-distearoylsn-glycero-3phosphoethanolamine-N-carboxy-carboxy(polyethylene glycol) to form a PEG shell providing electrostatic and steric stabilizations, a longer circulation half-life in vivo as well as functional-end groups for the attachment of targeting ligands such as antibodies, peptides and aptamers [118]. Furthermore, phosphate-functional core-shell nanoparticles composed of a polystyrene core and a shell of cross-linked polymers (alkenyl phosphate binding) were recently formulated for the bioactive release of vascular endothelial growth factors in potential angiogenesis applications [2]. The controlled release properties of synthetic polymers have been combined with the biocompatibility of natural polymers in recent years; forming polymeric composites. Examples include PLGA-gelatin composites, collagen-PLG-alginate composites, and hyaluronanimpregnated PLA sponges [120,121]. PLGA nanospheres immobilized onto prefabricated nanofibrous PLLA scaffolds were used to load a specific BMP (BMP-7, also known as osteogenic protein-1 or OP-1) and to promote in vivo bone regeneration [122]. However, significant failure of bone induction was observed due to loss of the bioactivity of the loaded protein and rapid release from the scaffolds once implanted subcutaneously in rats [122]. In a recent review [9], carrier biomaterials, particularly natural and synthetic polymers and their combinations in different formats for the delivery of growth factors to preclinical and clinical sites of bone regeneration and repair were classified and discussed. Applications of polymeric-based core-shell nanoparticulate systems allowing injectability, for example, will extend into a much broader range of orthopaedic as well as craniofacial and oro-dental implications including bone, cartilage and tendon/ligament (and periodontal) tissue regeneration and repair [9]. Surface charge is another important parameter in determining how nanoparticles interact with cells, whose membranes are usually negatively charged as emphasized at the inception of this review. Further, the morphology, hydrophobicity and size allows drugs to accumulate in solid tumours, which are characterized by 
extensive angiogenesis, defective vascular architecture, impaired lymphatic drainage and an increased production of permeability factors $[123,124]$. The fundamental physiochemical properties for an efficacious and safe nanoparticulate drug delivery specific within a tumor microenvironment; depending on cancer type, stage of disease, site of implantation as well as host species were recently studied by Adiseshaiah et al. [125]. Some surface modification methods may even allow the use of polymeric micelles as coating materials for tissue engineering scaffolds. It has been indicated that such drug-loaded micellar shells can exhibit controlled drug release [16,33,126,127] and hence, predictable and metered release (of one or more agents: simultaneous/sequential release) is possible from nanoscaffolds for drugs, genes or proteins, extending advantages to preventing infection or further enhancing tissue and organ regeneration [127].

\section{Miscellaneous Applications of Core-Shell Nanostructures}

As mentioned throughout this review, the applicable areas of nanoparticles are broad and not limited to nanomedicine. Nanoshells and core-shell preparations have gained considerable attention in clinical and therapeutic applications going far beyond drug delivery. Determining the core-to-shell ratio allows the design of novel efficient core-shell nanostructures which, as described earlier, can either absorb or scatter light [128]. Hence, former preparations find applications in photo-thermal therapy, while the latter can be used for imaging purposes. Polymeric-based core shell nanocomposites whether polymer-polymer or polymer-metal combinations have been investigated for use in the fabrication of dental braces as well as joint-, hip- and knee-replacements [21]. Ultra high molecular weight polyethylene-silver and polymer-coated titanium are such examples [129,130]. Dental resin-based composites, as restorative materials, possess good aesthetic properties and have replaced the traditional mercury-containing amalgam. Yet, amalgam continues to possess functional and mechanical superiority (water resistance and marginal shrinkage). Therefore, nanoparticle-reinforced dental resins have recently emerged. $\mathrm{Gu}$ and co-workers [131] studied $\mathrm{TiO}_{2}$ nanoparticles as an inorganic filler to overcome the drawbacks of traditional tougheners such as glass and rubber beads. In addition, the $\mathrm{TiO}_{2}$ nanoparticles were coated with an organosilane (allyltriethoxysilane) and blended into the resin matrix yielding overall improved micro-hardness and flexural strength than the controls [131]. In another approach aimed at enhancing the optical properties of dental resin biomaterials to match the fluorescence and emission spectra of natural human teeth, Munin and group [132] recently showed how the incorporation CdSe/ZnS core-shell QDs allows tailoring absorbance according to (a) QD nanocrystal concentration and (b) luminophore core size [132]. Furthermore, an artificial hybrid material was prepared from 15-18 nm ceramic nanoparticles coated with poly (methyl methacrylate) co-polymer [21,132,133] for applications in restorative and conservative dentistry given the scratch-resistant property of the material. Using a tri-bology approach, viscoelastic behaviour (healing) of human dentition was demonstrated [134]. Other nanostructures such as colloidal silver and titania are being used in medical dressings for quicker wound healing and in the design of filter materials for better and efficient separation of components, respectively [21,134]. It is worth mentioning that this application is not restricted only to the biological industry. Catalytic activity enhancement is also a dynamic field today [135,136]. Enzymes immobilized on core-shell nanoparticles or catalysts encapsulated suitably into nanoparticles are 
demonstrating higher activity than before with some having potential applications in biosensoring [135-137]. In a recent example, a shell composed of a poly( $\mathrm{N}$-isopropylacrylamide) network was grafted onto a solid polystyrene core. $\beta$-d-glucosidase (an almond-derived enzyme) was then adsorbed onto the thermosensitive microgel. The observed enzymatical activity enhancement was attributed to the strength of the interactions between the enzyme and the microgel by hydrogen bonds revealed via Fourier-transform infrared spectroscopy [135-137]. Besides spherical-shaped nanoparticles and nanoshell/nanopore membranes, another class of polymeric-based core-shell nanostructures that have attracted considerable interest is nanofibers, mainly formulated via high-voltaged electrospinning, for drug delivery purposes $[138,139]$. Further, co-axial electrospinning has been used to produce simple and cost-effective core-shell structured nanofibers suitable for the incorporation of proteins and achieving the delivery of biochemical signals in a controlled manner for regenerative medicine applications. Many polymers from the ones discussed herein have been also employed in the design, including chitosan, gelatin, PEO/PEG, PEO/PVP, PLGA, PCL and PVA. Encouraging results were obtained from such materials, forming special scaffolds that are morphologically similar to the extracellular matrix of natural tissues [138-140] providing an excellent platform for cell growth and tissue formation suitable for tissue engineering and wound healing indications following the incorporation of biologically- and therapeutically-active compounds [140,141]. Such applications include antibiotics [142], antifungal drugs [143], heparin (for prevention of vascular smooth-musclecell proliferation) [144], proteins [145-147] (such as platelet-derived growth factor with near zeroorder kinetics and preserved bioactivity) and plasmid DNA $[148,149]$ in addition to $\mathrm{SnO}_{2}-\mathrm{ZnO}$ coreshell nanofibers for dynamic biosensing [150] to name a few.

\section{Prospects}

As it stands now, polymer nanotechnology is rapidly expanding. At the same time, its biomimetic application to drug or nucleic acid delivery has offered unique opportunities for the inception of a variety of novel polymeric nanostructures, including core-shell architecture nanoparticles and nanofibers. Their demonstrated, outstanding potential stems from the ability to obtain structures with combinations of properties that neither individual material possesses alone. The majority of commercial natural polymer-incorporated nanoparticulate applications in medicine are geared towards bioactive, cost-effective and malleable therapeutic agent delivery. Still, bigger potentials for many other highly-demanded 'multi-functional' applications; including anti-tumour-, protein- peptide-, gene-, AIDS- and radio-therapy exist and will tailor the focus in the coming years. In biosciences, nanoparticles are replacing organic dyes in applications that require high photo-stability as well as high multiplexing capabilities. It is expected that core-shell nanomaterials will radically change the way we diagnose, treat and prevent disease. There are some developments in directing, targeting and remotely controlling the functions of nano-probes, for example, driving magnetic nanoparticles to the tumor and then making them either release their drug load or simply heat up to destroy the surrounding tissue of interest. The major trend in further development of nanomaterials is to make them, not only multi-functional, but also controllable by external signals or by local environment (barrier penetration) thus essentially turning them into 'smart' or 'intelligent' nano-devices facilitating in vivo imaging, and result reporting. Further, it is well-documented that nanoparticulate drug delivery 
systems have advantages over the conventional strategies. They can enhance the bioavailability, solubility and permeability of many potent drugs and short half-lived biological morphogens. Localized and release-controlled polymeric core-shell nanoparticles will also reduce the drug dosage frequency and thereby boost patient compliance. They can minimize some of the drugs' unique problems by safeguarding stability and preserving their structure. Hybrid nanoparticles provide ingenious treatment by enabling targeted delivery and controlled release with the further potential to combine diagnosis and therapy emerging as one of the major tools in nanomedicine. The main goals are to improve their stability in the biological environment, to mediate the bio-distribution of active compounds, improve drug loading and protection, targeting, transport, release, and interaction with biological barriers. Cytotoxicity and degradation by-products remain a major problem, and improvements in biocompatibility are a logical concern and focus of future research. Thus, stimuliresponsive protective layers; for example, whether in single or multiple assemblies, feasibly obtainable by polymeric core-shell designs, seem very capable in tackling such restrictive issues in the next 10 years, strengthening promises to provide therapy and cure.

\section{Acknowledgments}

This work was supported by the South Korean Ministry of Knowledge and Education (MKE) and the Incheon Free Economic Zone (IFEZ) in the framework of several funding operating grants to the Utah-Inha Drug Delivery Systems (DDS) and Advanced Therapeutics Research Center. Appreciation goes to Victor S Joo for proof-reading. Finally, the author reports no conflict of interest for the work.

\section{Reference}

1. Sahoo, S.K.; Labhasetwar, V. Nanotech approaches to drug delivery and imaging. Drug Discov. Today 2003, 8, 1112-1120.

2. Gilmore, J.L.; Yi, X.; Quan, L.; Kabanov, A.V. Novel Nanomaterials for Clinical Neuroscience. J. Neuroimmune Pharmacol. 2008, 3, 83-94.

3. Ramsden, J.J. What is nanotechnology? Nanotechnol. Percept. 2005, 1, 3-17.

4. Murray, C.B.; Kagan, C.R.; Bawendi, M.G. Synthesis and characterisation of monodisperse nanocrystals and close-packed nanocrystals assemblies. Annu. Rev. Mater. Sci. 2000, 30, 545-610.

5. Whitesides, G.M. The 'right' size in Nanobiotechnology. Nat. Biotech. 2003, 2, 1161-1165.

6. Parak, W.J.; Gerion, D.; Pellegrino, T.; Zanchet, D.; Micheel, C.; Williams, C.S.; Boudreau, R.; Le Gros, M.A.; Larabell, C.A.; Alivisatos, A.P. Biological applications of colloidal nanocrystals. Nanotechnology 2003, 14, R15-R27.

7. Pankhurst, Q.A.; Connolly, J.; Jones, S.K.; Dobson, J. Applications of magnetic nanoparticles in biomedicine. J. Phys. D Appl. Phys. 2003, 36, R167-R181.

8. Haidar, Z.S.; Hamdy, R.C.; Tabrizian, M. Delivery of recombinant bone morphogenetic proteins for bone regeneration and repair. Part A: Current challenges in BMP delivery. Biotechnol. Lett. 2009, 31, 1817-1824.

9. Haidar, Z.S.; Hamdy, R.C.; Tabrizian, M. Delivery of recombinant bone morphogenetic proteins for bone regeneration and repair. Part B: Delivery systems for BMPs in orthopaedic and craniofacial tissue engineering. Biotechnol. Lett. 2009, 31, 1825-1835. 
10. Yang, Y.Y.; Wang, Y.; Powell, R.; Chan, P. Polymeric core-shell nanoparticles for therapeutics. Clin. Exp. Pharm. Physio. 2006, 33, 557-562.

11. Lee, W.F.; Cheng, T.S. Synthesis and drug-release behavior of porous biodegradable amphiphilic co-polymeric hydrogels. J. Biomater. Sci. Polym. Ed. 2009, 20, 2023-2037.

12. Schärtl, W. Current directions in core-shell nanoparticle design. Nanoscale 2010, 2, 829-843.

13. Ranjan, A.; Pothayee, N.; Seleem, M.N.; Tyler, R.D. Jr.; Brenseke, B.; Sriranganathan, N.; Riffle, J.S.; Kasimanickam, R. Antibacterial efficacy of core-shell nanostructures encapsulating gentamicin against an in vivo intracellular Salmonella model. Int. J. Nanomed. 2009, 4, 289-297.

14. Ydens, I.; Degee, P.; Nouvel, C.; Dellacherie, E.; Six, J.L.; Dubois, P. Surfactant-free' stable nanoparticles from biodegradable and amphiphilic poly( $\varepsilon$-caprolactone)-grafted dextran copolymers. e-Polymers 2005, 46, 1-11.

15. Kumari, A.; Yadav, S.K.; Yadav, S.C. Biodegradable polymeric nanoparticles based drug delivery systems. Colloid. Surface. B 2010, 75, 1-18.

16. Finne-Wistrand, A.; Albertsson, A.C. The use of polymer design in resorbable colloids. Annu. Rev. Mater. Res. 2006, 36, 369-395.

17. Boscovic, B.O. Carbon nanotubes and nanofibres. Nanotechnol. Percept. 2007, 3, 141-158.

18. Zandonella, C. The tiny toolkit. Nature 2003, 423, 10-12.

19. Mazzola, L. Commercializing nanotechnology. Nat. Biotech. 2003, 21, 1137-1143.

20. Haidar, Z.S.; Hamdy, R.C.; Tabrizian, M. Protein release kinetics for core-shell hybrid nanoparticles based on the layer-by-layer assembly of alginate and chitosan on liposomes. Biomaterials 2008, 29, 1207-1215.

21. Sounderya, N.; Zhang, Y. Use of Core/Shell Structured Nanoparticles for Biomedical Applications. Recent Pat. Biomed. Eng. 2008, 1, 34-42.

22. Burda, C.; Chen, X.; Narayana, R.; El Sayed, M.A. Chemistry and Properties of Nanocrystals of Different Shapes. Chem. Rev. 2005, 105, 1025-1102.

23. Angelatos A.S.; Katagiri K.; Caruso F. Bioinspired colloidal systems via layer-by-layer assembly. Soft Matter. 2006, 2, 18-23.

24. Brigger, I.; Dubernet, C.; Couvreur, P. Nanoparticles in cancer therapy and diagnosis. Adv. Drug Deliv. Rev. 2002, 54, 631-651.

25. Papadimitriou, S.; Bikiaris, D. Novel self-assembled core-shell nanoparticles based on crystalline amorphous moieties of aliphatic copolyesters for efficient controlled drug release. $J$. Control. Release 2009, 138, 177-184.

26. Schreder, B.; Schmidt, T.; Ptatschek, V.; Spanhel, L.; Materny, A.; Kiefer, W. Raman characterization of CdTe/CdS-core-shell-clusters in colloids and films. J. Cryst. Growth 2000, $214,782-786$.

27. Chu, M.Q.; Cheng, D.L.; Zhu, J. Preparation of quantum dotcoated magnetic polystyrene nanospheres for cancer cell labelling and separation. Nanotecnology 2006, 17, 3268-3273.

28. Zhou, M.; Gho, I. Quantum dots and peptides: A bright future together. Pept. Sci. 2006, 88, 325-339.

29. Sandros, M.G.; Shete, V.; Benson, D.E. Selective, reversible, reagentless maltose biosensing with core-shell semiconducting nanoparticles. Analyst 2006, 131, 229-235. 
30. Kang, D,Y.; Kim, M.J.; Kim, S.T.; Oh, K.S.; Yuk, S.H.; Lee, S. Size characterization of drug-loaded polymeric core/shell nanoparticles using asymmetrical flow field-flow fractionation. Anal. Bioanal. Chem. 2008, 390, 2183-2188.

31. Chilcott, J.; Lloyd Jones, M.; Wilkinson, A. Docetaxel for the adjuvant treatment of early node-positive breast cancer: a single technology appraisal. Health Technol. Assess. 2009, 13, 7-11.

32. Wei, Z.; Hao, J.; Yuan, S.; Li, Y.; Juan, W.; Sha, X.; Fang, X. Paclitaxel-loaded Pluronic P123/F127 mixed polymeric micelles: formulation, optimization and in vitro characterization. Int. J. Pharm. 2009, 376, 176-185.

33. Sethuraman, V.A.; Bae, Y.H. TAT peptide-based micelle system for potential active targeting of anti-cancer agents to acidic solid tumors. J. Contol. Release 2007, 118, 216-224.

34. Borini, S.; D'Auria, S.; Rossi, M.; Rossi, A.M. Writing 3D protein nanopatterns onto a silicon nanosponge. Lab Chip 2005, 5, 1048-1052.

35. Gupta, P.; Vermani, K.; Garg, S., Hydrogels: from controlled release to pH-responsive drug delivery. Drug Discov. Today 2002, 7, 569-579.

36. Kojima, C. Design of stimuli-responsive dendrimers. Expert Opin. Drug Deliv. 2010, 7, 307-319.

37. Alves, N.M.; Mano, J.F. Chitosan derivatives obtained by chemical modifications for biomedical and environmental applications. Int. J. Biol. Macromol. 2008, 43, 401-414.

38. Kuroda, Y.; Kuroda, K. Layer-by-layer assembly of imogolite nanotubes and polyelectrolytes into core-shell particles and their conversion to hierarchically porous spheres. Sci. Technol. Adv. Mater. 2008, 9, 250-218.

39. Srivastava, S.; Kotov, N.A. Composite Layer-by-Layer (LBL) assembly with inorganic nanoparticles and nanowires. Account Chem. Res. 2008, 12, 1831-1841.

40. Owens, D.E. III; Peppas, N.A. Opsonization, biodistribution, and pharmacokinetics of polymeric nanoparticles. Int. J. Pharm. 2006, 307, 93-102.

41. Preston, T.C.; Signorell, R. Growth and optical properties of gold nanoshells prior to the formation of a continuous metallic layer. ACS Nano. 2009, 3, 3696-3706.

42. Park, J.H.; Ye, M.; Park, K. Biodegradable polymers for microencapsulation of drugs. Molecules 2005, 10, 146-161.

43. Azzam, T.; Eisenberg, A. Monolayer-protected gold nanoparticles by the self-assembly of micellar poly(ethylene oxide)-b-poly(epsilon-caprolactone) block copolymer. Langmuir 2007, 23, 2126-2132.

44. Ramzi, A.; Rijcken, C.J.; Veldhuis, T.F.; Schwahn, D.; Hennink, W.E.; van Nostrum, C.F. Core-shell structure of degradable, thermosensitive polymeric micelles studied by small-angle neutron scattering. J. Phys. Chem. B 2008, 112, 784-792.

45. Haidar, Z.S.; Tabrizian, M.; Hamdy, R.C. A hybrid rhOP-1 delivery system enhances new bone regeneration and consolidation in a rabbit model of distraction osteogenesis. Growth Factors 2010, 28, 44-55.

46. Haidar, Z.S.; Hamdy, R.C.; Tabrizian, M. Biocompatibility and safety of a hybrid core-shell nanoparticulate OP-1 delivery system intramuscularly administered in rats. Biomaterials 2010, $31,2746-2754$. 
47. Haidar, Z.S.; Azari, F.; Hamdy, R.C.; Tabrizian, M. Modulated release of OP-1 and enhanced preosteoblast differentiation using a core-shell nanoparticulate system. J. Biomed. Mater. Res. A 2009, 91, 919-928.

48. Zhang, J.; Misra, R.D.K. Magnetic drug-targeting carrier encapsulated with thermosensitive smart polymer: Core-shell nanoparticle carrier and drug release response. Acta Biomater. 2007, 3, 838-850.

49. Surendiran, A.; Sandhiya, S.; Pradhan, S.C.; Adithan, C. Novel applications of nanotechnology in medicine. Indian J. Med. Res. 2009, 130, 689-701.

50. Santander-Ortega, M.J.; Bastos-González, D.; Ortega-Vinuesa, J.L. Electrophoretic mobility and colloidal stability of PLGA particles coated with IgG. Colloid. Surface B 2007, 60, 80-88.

51. Sant, S.; Poulin, S.; Hildgen, P. Effect of polymer architecture on surface properties, plasma protein adsorption, and cellular interactions of pegylated nanoparticles. J. Biomed. Mater. Res. A 2008, 87, 885-895.

52. West, J.L. Biofunctional Polymers. Encycl Biomater. Biomed. Eng. 2004, 1, 89-95.

53. Wissink, M.J.B.; Beernink, R.; Poot, A.A.; Engbers, G.H.M.; Beugling, T.; van Aken, W.G.; Feijen, J. Improved endothelialization of vascular grafts by local release of growth factor from heparinized collagen matrices. J. Control. Release 2000, 64, 103-114.

54. Mann, B.K.; Schmedlen, R.H.; West, J.L. Tethered TGFbeta increases extracellular matrix production of vascular smooth muscle cells. Biomaterials 2001, 22, 439-444.

55. Moon, J.J.; West J.L. Vascularization of Engineered Tissues: Approaches to Promote Angiogenesis in Biomaterials. Curr. Top. Med. Chem. 2008, 8, 300-310.

56. Klonoff, D.C. Technological advances in the treatment of diabetes mellitus: better bioengineering begets benefits in glucose measurement, the artificial pancreas, and insulin delivery. Pediatr. Endocrinol. Rev. 2003, 2, 94-100.

57. Pickup, J.C.; Zhi, Z.L.; Khan, F.; Saxl, T.; Birch, D.J. Nanomedicine and its potential in diabetes research and practice. Diabetes Metab. Res. Rev. 2008, 24, 604-610.

58. Chang, A.; Orth, A.; Le, B.; Menchavez, P.; Miller, L. Performance Analysis of the OneTouch(R) UltraVue Blood Glucose Monitoring System. J. Diabetes Sci. Technol. 2009, 3, $1158-1165$.

59. Wang, J.; Musameh, M. Enzyme-dispersed carbon-nanotube electrodes: a needle microsensor for monitoring glucose. Analyst 2003, 128, 1382-1385.

60. Cai, C.; Chen, J. Direct electron transfer of glucose oxidase promoted by carbon nanotubes. Anal. Biochem. 2004, 332, 75-83.

61. Lee, S.H.; Lee, H.; Park, J.S.; Choi, H.; Han, K.Y.; Seo, H.S.; Ahn, K.Y.; Han, S.S.; Cho, Y.; Lee, K.H.; Lee, J. A novel approach to ultrasensitive diagnosis using supramolecular protein nanoparticles. FASEB J. 2007, 21, 1324-1334.

62. Duong, H.D.; Rhee, J.I. Use of $\mathrm{CdSe} / \mathrm{ZnS}$ core-shell quantum dots as energy transfer donors in sensing glucose. Talanta 2007, 73, 899-905.

63. Véronique, L.V.; Anclaa, C.; Catargic, B.; Ravaine, V. Glucose-responsive microgels with a core-shell structure. J. Colloid. Interface Sci. 2008, 327, 316-323.

64. Ramesan, R.M.; Sharma, C.P. Challenges and advances in nanoparticle-based oral insulin delivery. Expert Rev. Med. Devices 2009, 6, 665-676. 
65. Scodeller, P.; Flexer, V.; Szamocki, R.; Calvo, E.J.; Tognalli N.; Troiani H.; Fainstein A. Wired-Enzyme Core-Shell Au Nanoparticle Biosensor. J. Am. Chem. Soc. 2008, 130, 12690-12697.

66. Lee, P.W.; Hsu, S.H.; Wang, J.J.; Tsai, J.S.; Lin, K.J.; Wey, S.P.; Chen, F.R.; Lai, C.H.; Yen, T.C.; Sung, H.W. The characteristics, biodistribution, magnetic resonance imaging and biodegradability of superparamagnetic core-shell nanoparticles. Biomaterials 2010, 31, 1316-1324.

67. Purushotham, S.; Chang, P.E.; Rumpel, H.; Kee, I.H.; Ng, R.T.; Chow, P.K.; Tan, C.K.; Ramanujan, R.V. Thermoresponsive core-shell magnetic nanoparticles for combined modalities of cancer therapy. Nanotechnology 2009, 20, 305101.

68. Choi, H.S.; Liu, W.; Liu, F.; Nasr, K.; Misra, P.; Bawendi, M.G.; Frangioni, J.V. Design considerations for tumour-targeted nanoparticles. Nat. Nanotech. 2010, 5, 42-47.

69. Zhu, X.; Duan, D.; Publicover, N.G. Magnetic bead based assay for C-reactive protein using quantum-dot fluorescence labeling and immunoaffinity separation. Analyst 2010, 135, 381-389.

70. Xu, H.; Sha, M.Y.; Wong, E.Y.; Uphoff, J.; Xu, Y.; Treadway, J.A.; Truong, A.; O'Brien, E.; Asquith, S.; Stubbins, M.; Spurr, N.K.; Lai, E.H.; Mahoney, W. Multiplexed SNP genotyping using the Qbead system: A quantum dot-encoded microsphere-based assay. Nucl. Acid. Res. 2003, 31, 43.

71. Behrendt, M.; Sandros, M.G.; McKinney, R.A.; McDonald, K.; Przybytkowski, E.; Tabrizian, M.; Maysinger, D. Imaging and organelle distribution of fluorescent $\mathrm{InGaP} / \mathrm{ZnS}$ nanoparticles in glial cells. Nanomedicine (London) 2009, 4, 747-761.

72. Kim, M.J.; Park, H.Y.; Kim, J.; Ryu, J.; Hong, S.; Han, S.J.; Song, R. Western blot analysis using metal-nitrilotriacetate conjugated $\mathrm{CdSe} / \mathrm{ZnS}$ quantum dots. Anal. Biochem. 2008, 379, 124-126.

73. Shiohara, A.; Hanada, S.; Prabakar, S.; Fujioka, K.; Lim, T.H.; Yamamoto, K.; Northcote, P.T.; Tilley, R.D. Chemical reactions on surface molecules attached to silicon quantum dots. J. Am. Chem. Soc. 2010, 132, 248-253.

74. Zhang, H.; Sachdev, D.; Wang, C.; Hubel, A.; Gaillard-Kelly, M.; Yee, D. Detection and downregulation of type I IGF receptor expression by antibody-conjugated quantum dots in breast cancer cells. Breast Cancer Res. Treat. 2009, 114, 277-285.

75. Kolter, T.; Sandhoff, K. Principles of Lysosomal Membrane Digestion: Stimulation of Sphingolipid Degradation by Sphingolipid Activator Proteins and Anionic Lysosomal Lipids. Ann. Rev. Cell Develop. Biol. 2005, 21, 81-103.

76. Sadik, O.A.; Zhou, A.L.; Kikandi, S.; Du, N.; Wang, Q.; Varner, K. Sensors as tools for quantitation, nanotoxicity and nanomonitoring assessment of engineered nanomaterials. $J$. Environ. Monit. 2009, 11, 1782-1800.

77. Hauck, T.S.; Anderson, R.E.; Fischer, H.C.; Newbigging, S.; Chan, W.C. In vivo quantum-dot toxicity assessment. Small 2010, 6, 138-134.

78. Susumu, K.; Uyeda, H.T.; Medintz, I.L.; Mattoussi, H. Design of biotin-functionalized luminescent quantum dots. J. Biomed. Biotechnol. 2007, 7, 90651.

79. Susumu, K.; Uyeda, H.T.; Medintz, I.L.; Pons, T.; Delehanty, J.B.; Mattoussi, H. Enhancing the stability and biological functionalities of quantum dots via compact multifunctional ligands. $J$. Am. Chem. Soc. 2007, 129, 13987-13996. 
80. Lee, J.; Kim, J.; Park, E.; Jo, S.; Song, R. PEG-ylated cationic CdSe/ZnS QDs as an efficient intracellular labeling agent. Phys. Chem. Chem. Phys. 2008, 10, 1739-1742.

81. Jia, H.; Titmuss, S. Polymer-functionalized nanoparticles: from stealth viruses to biocompatible quantum dots. Nanomedicine (London) 2009, 4, 951-966.

82. Aillon, K.L.; Xie, Y.; El-Gendy, N.; Berkland, C.J.; Forrest, M.L. Effects of nanomaterial physicochemical properties on in vivo toxicity. Adv. Drug Deliv. Rev. 2009, 61, 457-466.

83. Hotz, C.Z. Applications of quantum dots in biology: An overview. Meth. Mol. B. 2005, 303, 1-17.

84. Haigron, P.; Dillenseger, J.L.; Luo, L.; Coatrieux, J.L. Image-Guided Therapy: Evolution and Breakthrough [A Look At]. IEEE Eng. Med. Biol. Mag. 2010, 29, 100-104.

85. Saravanakumar, G.; Kim, K.; Park, J.H.; Rhee, K.; Kwon, I.C. Current status of nanoparticlebased imaging agents for early diagnosis of cancer and atherosclerosis. J. Biomed. Nanotechnol. 2009, 5, 20-35.

86. Ozpolat, B.; Sood, A.K.; Lopez-Berestein, G. Nanomedicine based approaches for the delivery of siRNA in cancer. J Intern. Med. 2010, 267, 44-53.

87. Wu, W.; Aiello, M.; Zhou, T.; Berliner, A.; Banerjee, P.; Zhou, S. In situ immobilization of quantum dots in polysaccharide-based nanogels for integration of optical $\mathrm{pH}$-sensing, tumor cell imaging, and drug delivery. Biomaterials 2010, 31, 3023-3031.

88. Orive, G.; Hernández, R.M.; Gascón, A.R.; Pedraz, J.L. Micro and nano drug delivery systems in cancer therapy. Cancer Ther. 2005, 3, 131-138.

89. Lissett, B.R.; Chang, J.; Fu, K.; Sun, J.; Hu, Y.; Gobin, A.; Yu, T.; Drezek, R.A. Evaluation of Immunotargeted Gold Nanoshells as Rapid Diagnostic Imaging Agents for HER2Overexpressing Breast Cancer Cells: A Time-based Analysis. Nanobiotechnology 2008, 4, 1-8.

90. Bickford, L.R.; Agollah, G.; Drezek, R.; Yu, T.K. Silica-gold nanoshells as potential intraoperative molecular probes for HER2-overexpression in ex vivo breast tissue using near-infrared reflectance confocal microscopy. Breast Cancer Res. Treat. 2009, 120, 547-555.

91. Wang, C.; Chen, J.; Talavage, T. Gold nanorod/Fe3O4 nanoparticle "nano-pearl-necklaces" for simultaneous targeting, dual-mode imaging, and photothermal ablation of cancer cells. Angew Chem. Int. Ed. Engl. 2009, 48, 2759-2763.

92. Kayal, S.; Ramanujan, R.V. Anti-Cancer Drug Loaded Iron-Gold Core-Shell Nanoparticles (Fe@Au) for Magnetic Drug Targeting. J. Nanosci. Nanotechnol. 2010, 10, 1-13.

93. Kapoor, Y.; Thomas, J.C.; Tan, G.; John, V.T.; Chauhan, A. Surfactant-laden soft contact lenses for extended delivery of ophthalmic drugs. Biomaterials 2009, 30,867-878.

94. Xinming, L.; Yingde, C.; Lloyd, A.W.; Mikhalovsky, S.V.; Sandeman, S.R.; Howel, C.A.; Liewen, L. Polymeric hydrogels for novel contact lens-based ophthalmic drug delivery systems: A review. Contact Lens \& Anterior Eye 2008, 31, 57-64.

95. Lü, J.M.; Wang, X.; Marin-Muller, C.; Wang, H.; Lin, P.H.; Yao, Q.; Chen, C. Current advances in research and clinical applications of PLGA-based nanotechnology. Expert Rev. Mol. Diagn. 2009, 9, 325-341.

96. Mahmud, A.; Xiong, X.B.; Aliabadi, H.M.; Lavasanifar, A. Polymeric micelles for drug targeting. J. Drug Targeting 2007, 15, 553-584. 
97. Panda, J.J.; Mishra, A.; Basu, A.; Chauhan, V.S. Stimuli responsive self-assembled hydrogel of a low molecular weight free dipeptide with potential for tunable drug delivery. Biomacromolecules 2008, 9, 2244-2250.

98. Van Tomme, S.R.; Storm, G.; Hennink, W.E. In situ gelling hydrogels for pharmaceutical and biomedical applications. Int. J. Pharm. 2008, 355, 1-18.

99. Mincheva, R.; Bougard, F.; Paneva, D.; Vachaudez, M.; Manolova, N.; Rashkov, I.; Dubois, P. Natural polyampholyte-based core-shell nanoparticles with $\mathrm{N}$-carboxyethylchitosan-containing core and poly(ethylene oxide) shell. Biomacromolecules 2009, 10, 838-844.

100. Mastrobattista, E.; van der Aa, M.A.E.M.; Hennink, W.E.; Crommelin, D.J.A. Artificial viruses: A nanotechnological approach to gene delivery. Nat. Rev. 2006, 5, 115-121.

101. Liu, Z.; Jiao, Y.; Wang, Y.; Zhou, C.; Zhang, Z. Polysaccharides-based nanoparticles as drug delivery systems. Adv. Drug Deliv. Rev. 2008, 60, 1650-1662.

102. Mano, J.F. Stimuli-Responsive Polymeric Systems for Biomedical Applications. Adv. Eng. Mat. 2008, 10, 515-527.

103. Thierry, B.; Winnik, F.M.; Merhi, Y.; Silver, J.; Tabrizian, M. Bioactive coatings of endovascular stents based on polyelectrolyte multilayers. Biomacromolecules 2003, 4, 1564-1571.

104. Quinn, J.F.; Caruso, F. Facile tailoring of film morphology and release properties using layer-bylayer assembly of thermoresponsive materials. Langmuir 2004, 20, 20-22.

105. Decher, G. Fuzzy nanoassemblies: toward layered polymeric multicomposites. Science 1997, 277, 1232-1237.

106. Yap, H.P.; Quinn, J.F.; Ng, S.M.; Cho, J.; Caruso, F. Colloid surface engineering via deposition of multilayered thin films from polyelectrolyte blend solutions. Langmuir 2005, 21, 4328-4333.

107. Takeuchi, H.; Kojima, H.; Yamamoto, H.; Toshitada, T.; Hidekazu, T.; Tomaoki, H. Physical stability of size controlled small unilamellar liposomes coated with a modified polyvinyl alcohol. Int. J. Pharm. 1998, 164, 103-111.

108. Galovic, R.R.; Barisic, K.; Pavelic, Z.; Zanic, G.T.; Cepelak, I.; Filipovic-Grcic, J. High efficiency entrapment of superoxide dismutase into mucoadhesive chitosan-coated liposomes. Eur. J. Pharm. Sci. 2002, 15, 441-448.

109. Hillberg, A.L.; Tabrizian, M. Biorecognition through layer-by-layer polyelectrolyte assembly: In-situ hybridization on living cells. Biomacromolecules 2006, 7, 2742-2750.

110. Douglas, K.L.; Tabrizian, M. Effect of experimental parameters on the formation of alginate-chitosan nanoparticles and evaluation of their potential application as DNA carrier. $J$. Biomater. Sci. Polym. Ed. 2005, 16, 43-56.

111. Gref, R.; Minamitake, Y.; Perracchia, M.T.; Trubeskoy, V.; Torchilin, V.; Langer, R. Biodegradable long-circulating polymeric nanospheres. Science 1994, 263, 1600-1603.

112. Desai, M.P.; Labhasetwar, V.; Amidon, G.L.; Levy, R.J. Gastrointestinal uptake of biodegradable microparticles: effect of particle size. Pharm. Res. 1996, 13, 1838-1845.

113. Kim, H.D.; Valentini, R.F. Retention and activity of BMP-2 in hyaluronic acid-based scaffolds in vitro. J. Biomed. Mater. Res. 2002, 59, 573-584.

114. Sydow-Plum, G.; Haidar, Z.S.; Merhi, Y.; Tabrizian, M. Modulating the Release Kinetics of Paclitaxel from Membrane-Covered Stents Using Different Loading Strategies. Materials 2008, $1,25-43$. 
115. Douglas, K.L.; Piccirillo, C.A.; Tabrizian, M. Effects of alginate inclusion on the vector properties of chitosan-based nanoparticles. J. Control. Release 2006, 27, 354-361.

116. Gelderblom, H.; Verweij, J.; Nooter, K.; Sparreboom, A. Cremophor EL: the drawbacks and advantages of vehicle selection for drug formulation. Eur. J. Cancer 2001, 37, 1590-1598.

117. Wu, S.Y.; McMillan, N.A. Lipidic systems for in vivo siRNA delivery. AAPS J. 2009, 11, 639-652.

118. Franzen, S.; Lommel, S.A. Targeting cancer with 'smart bombs': equipping plant virus nanoparticles for a 'seek and destroy' mission. Nanomed (London) 2009, 4, 575-588.

119. Chan, J.M.; Zhang, L.; Yuet, K.P.; Liao, G.; Rhee, J.W.; Langer, R.; Farokhzad, O.C. PLGA-lecithin-PEG core-shell nanoparticles for controlled drug delivery. Biomaterials 2009, 30, 1627-1634.

120. Kenley, R.; Marden, L.; Turek, T.; Jin, L.; Ron, E.; Hollinger, J.O. Osseous regeneration in the rat calvarium using novel delivery systems for recombinant human bone morphogenetic protein-2 (rhBMP-2). J. Biomed. Mater. Res. 1994, 28, 1139-1147.

121. Higuchi, T.; Kinoshita, A.; Takahashi, K.; Oda, S.; Ishikawa, I. Bone regeneration by recombinant human bone morphogenetic protein-2 in rat mandibular defects. An experimental model of defect filling. J. Periodontol. 1999, 70, 1026-1031.

122. Wei, G.; Jin, Q.; Giannobile, W.V.; Ma, P.X. The enhancement of osteogenesis by nano-fibrous scaffolds incorporating rhBMP-7 nanospheres. Biomaterials 2007, 28, 2087-2096.

123. Corsi, F.; De Palma, C.; Colombo, M.; Allevi, R.; Nebuloni, M.; Ronchi, S.; Rizzi, G.; Tosoni, A.; Trabucchi, E.; Clementi, E.; Prosperi, D. Towards ideal magnetofluorescent nanoparticles for bimodal detection of breast-cancer cells. Small 2009, 5, 2555-2564.

124. Chung, Y.I.; Kim, J.C.; Kim, Y.H.; Tae, G.; Lee, S.Y.; Kim, K.; Kwon, I.C. The effect of surface functionalization of PLGA nanoparticles by heparin- or chitosan-conjugated Pluronic on tumor targeting. J. Control. Release 2010, 143, 374-382.

125. Adiseshaiah, P.P.; Hall, J.B.; McNeil, S.E. Nanomaterial standards for efficacy and toxicity assessment. Wiley Interdiscip. Rev. Nanomed. Nanobiotechnol. 2010, 2, 99-112.

126. Osada, K.; Christie, J.R.; Kataoka, K. Polymeric micelles from poly(ethylene glycol)-poly(amino acid) block copolymer for drug and gene delivery. J. R. Soc. Interface 2009, 6, S325-S339.

127. Ma, P.X. Biomimetic Materials for Tissue Engineering. Adv. Drug Deliv. Rev. 2008, 60, 184-198.

128. Gobin, A.M.; Lee, M.H.; Halas, N.J.; James, W.D.; Drezek, R.A.; West, J.L. Near-Infrared Resonant Nanoshells for Combined Optical Imaging and Photothermal Cancer Therapy. Nano Lett. 2007, 7, 1929-1934.

129. Yu, B.; Ahn, J.S.; Lim, J.I.; Lee, Y.K. Influence of TiO2 nanoparticles on the optical properties of resin composites. Dent. Mater. 2009, 25, 1142-1147.

130. Kim, K.H.; Ramaswamy, N. Electrochemical surface modification of titanium in dentistry. Dent. Mater. 2009, 28, 20-36.

131. Xiaa, Y.; Zhanga, F.; Xiea, H.; Gub, N. Nanoparticle-reinforced resin-based dental composites. J. Dentistry 2008, 36, 450-455.

132. Alves, L.P.; Pilla, V.; Murgo, D.O.A.; Munin E. Core-shell quantum dots tailor the fluorescence of dental resin composites. J. Dentistry 2010, 38, 149-152. 
133. Moszner, N.; Klapdohr, S. Nanotechnology for dental composites. Int. J. Nanotechnol. 2004, 1, $130-156$.

134. De la Isla, A.; Brostow, W.; Bujard, B.; Estevez, M.; Rodriguez, J.R.; Vargas, S.; Castano, V.M. Nanohybrid scratch resistant coating for teeth and bone viscoelasticity manifested in tribology. Mater. Res. Innov. 2003, 7, 110-114.

135. Berube, D.M. The magic of nano. Nanotechnol. Percept. 2006, 2, 249-255.

136. Ballauff, M.; Lu, Y. "Smart" Nanoparticles: Preparation, Characterization and Applications. Polymer 2007, 48, 1815-1823.

137. Welsch, N.; Wittemann, A.; Ballauff, M. Enhanced activity of enzymes immobilized in thermoresponsive core-shell microgels. J. Phys. Chem. B 2009, 113, 16039-16045.

138. Pham, Q.P.; Sharma, U.; Mikos, G. A. Electrospinning of Polymeric Nanofibers for Tissue Engineering Applications: A Review. Tissue Eng. 2006, 12, 1197-1211.

139. Pillai, C.K.S.; Sharma, C. P. Electrospinning of Chitin and Chitosan Nanofibres. Trends Biomater. Artif. Organ. 2009, 22, 179-201.

140. Liao, I.C.; Chew, S.Y.; Leong, K.W. Aligned core-shell nanofibers delivering bioactive proteins. Nanomedicine 2006, 1, 465-471.

141. Katti, D.S.; Robinson, K.W.; Ko, F.K.; Laurencin, C.T. Bioresorbable nanofiber-based systems for wound healing and drug delivery: optimization of fabrication parameters. Biomed. Mater. Res. B Appl. Biomater. 2004, 70, 286-296.

142. Tian, X.; Fei, J.; Pi, Z.; Yang, C.; Luo, D. Synthesis and characterization of amoxicillin nanostructures. Nanomedicine 2005, 1, 323-325.

143. Ignatova, M.; Markova, N.; Manolova, N.; Rashkov, I. Antibacterial and antimycotic activity of a cross-linked electrospun poly(vinyl pyrrolidone)-iodine complex and a poly(ethylene oxide)/poly(vinyl pyrrolidone)-iodine complex. J. Biomater. Sci. Polym. Ed. 2008, 19, 373-386.

144. Su, Y.; Li, X.; Liu, Y.; Su, Q.; Qiang, M.L.; Mo, X. Encapsulation and Controlled Release of Heparin from Electrospun Poly(L-Lactide-co-epsilon-Caprolactone) Nanofibers. J. Biomater. Sci. Polym. Ed. 2010, in print.

145. Dubois, G.; Segers, V.F.; Bellamy, V.; Sabbah, L.; Peyrard, S.; Bruneval, P.; Hagège, A.A.; Lee, R.T.; Menasché, P. Self-assembling peptide nanofibers and skeletal myoblast transplantation in infarcted myocardium. J. Biomed. Mater. Res. B Appl. Biomater. 2008, 87, 222-228.

146. Hsieh, P.C.; Davis, M.E.; Gannon, J.; MacGillivray, C.; Lee, R.T. Controlled delivery of PDGF-BB for myocardial protection using injectable self-assembling peptide nanofibers. J. Clin. Invest. 2006, 116, 237-248.

147. Hosseinkhani, H.; Hosseinkhani, M.; Khademhosseini, A.; Kobayashi, H. Bone regeneration through controlled release of bone morphogenetic protein-2 from 3-D tissue engineered nano-scaffold. J. Control. Release 2007, 117, 380-386.

148. Kaji, N.; Okamoto, Y.; Tokeshi, M.; Baba, Y. Nanopillar, nanoball, and nanofibers for highly efficient analysis of biomolecules. Chem. Soc. Rev. 2010, 39, 948-956.

149. McKnight, T.E.; Melechko, A.V.; Guillorn, M.A.; Merkulov, V.I.; Lowndes, D.H.; Simpson, M.L. Synthetic nanoscale elements for delivery of materials into viable cells. Methods Mol. B. 2005, 303, 191-208. 
150. Choi, S.W.; Park, J.Y.; Kim, S.S. Synthesis of SnO2-ZnO core-shell nanofibers via a novel two-step process and their gas sensing properties. Nanotechnology 2009, 20, 465603.

(C) 2010 by the authors; licensee MDPI, Basel, Switzerland. This article is an open access article distributed under the terms and conditions of the Creative Commons Attribution license (http://creativecommons.org/licenses/by/3.0/). 